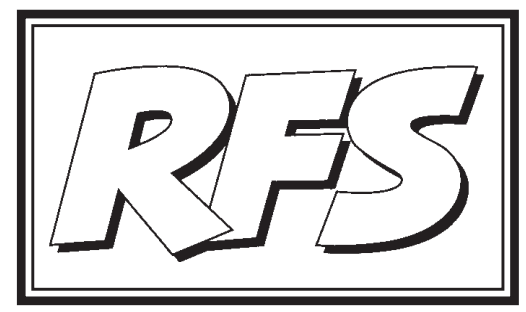

Revista de Fomento Social, 61 (2006), 319-360

\title{
Justicia y amor: dos dimensiones, una realidad. Sobre la encíclica Deus caritas est
}

(Palabras clave: Caridad, Doctrina Soctal Cristiana, Estado, Justicia, Orden Social, Política, SubsidiaRIEDAD, VoluntaRIado.

Key words: Love, Social Christian Doctrine, State, Justice, Social Order, Politics, SUBSIDIARY, VOLUNTARY)

\section{Introducción}

La encíclica Deus caritas est ${ }^{1}$ deBenitoXVI, publicada el 25 de enero de 2006 , es su primer gran texto doctrinal como Papa, "sin duda unaEncíclica programática,

1 Dios es amor (a partir de ahora citaré DCE). Aunque firmada el 25-XII-2005, fue publicada el 25-I-2006. 
en el sentido más alto y comprometido" de la palabra. ${ }^{2}$ La encíclica contiene una reflexión teológica sobre el amor y algunas consideraciones sobre las relaciones entre los ámbitos del amor y de la justicia, sobre el servicio eclesial de la caridad y sobre el voluntariado. El documento se ordena en dos grandes partes: el amor de Dios al hombre y la respuesta humana al amor de Dios. En este artículo me refiero, sobre todo, a la justicia como forma determinante de esa respuesta al amor de Dios, por lo que, aun sin tratar detenidamente sobre la primera parte, la consagrada al amor, creo acertado proponer la profunda unidad de la justicia y la caridad como dimensiones de una misma realidad.

La opción fundamental (DCE 1:2) ${ }^{3}$ del cristiano nace de un acontecimiento: el encuentro con la persona de Jesucristo que da una orientación decisiva a la vida del creyente. Desde las primeras líneas queda enunciada la afirmación, que recorre todo el texto, del primado no sólo temporal, sino ontológico, del encuentro personal; de éste surge la existencia creyente, que es la respuesta al don del amor (DCE 1:2). Para la encíclica lo ético o lo doctrinal ocupan una posición "segunda", tras el acontecimiento cristiano del amor entregado y del amor como respuesta, que es "primero". El fundamento de esta afirmación reside en la formulación sintética de la existencia cristiana (DCE 1:1) de la primera carta del evangelista Juan: «Nosotros hemos conocido el amor que Dios nos tiene y hemos creído en él» (1 Jn 4:16).

Benito XVI dedica su primera encíclica al amor, un amor que es don de Dios y que es también un don a comunicar a los demás. El Papa divide su texto en dos partes, intrínsecamente conexas, aunque puedan leerse como dos piezas distintas ${ }^{4}$. Él mismo explica, al principio, que

2 Según el cardenal Renato R. Martino, presidente de Iustitia et Pax, en la conferencia de prensa de presentación. Vid. www.vatican.va/news services/bulletin/news, consultada el 25-I-2006.

3 Las expresiones tomadas literalmente aparecerán en cursivas, seguidas de la referencia a la encíclica, entre paréntesis (citaré el número correspondiente de la edición oficial utilizada, seguido de dos puntos [:] a los que seguirá otro número que indica el párrafo dentro de cada número según orden secuencial). He consultado (25-I-2006) la versión castellana de la página de la Santa Sede: www.vatican.va Si hubiere alguna variación importante en relación a la edición en papel, por ejemplo la de editorial Católica (BAC-documentos 32), Madrid 2006, 70 pp., quedará anotado en su momento. Quiero dejar constancia de las generosas y amables observaciones de mis compañeros del consejo de redacción a una primera versión escrita de este texto, que pudimos dialogar y que espero haber recogido con acierto (especialmente a Ildefonso Camacho). En cualquier caso los errores son exclusivamente míos.

4 Sorge, cf. l'Osservatore romano, Ciudad del Vaticano, 23/24-I-2006. 
(...) las dos grandes partes (... están) íntimamente relacionadas entre sí. La primera tendrá un carácter más especulativo, puesto que en ella quisiera precisar (...) algunos puntos esenciales sobre el amor que Dios, de manera misteriosa y gratuita, ofrece al hombre y, a la vez, la relación intrínseca de dicho amor con la realidad del amor humano. La segunda parte (...) más concreta (...) tratará de cómo cumplir de manera eclesial el mandamiento del amor al prójimo (DCE 1:3).

Aunque el tema del documento sea sumamente amplio, el propósito del autor no es ofrecer un tratado exhaustivo, sino

insistir sobre algunos elementos fundamentales, para suscitar en el mundo un renovado dinamismo de compromiso en la respuesta humana al amor divino (DCE 1:3).

El contexto de la encíclica puede aclarar también algo su sentido. El documento se publica al principio de un pontificado marcado por el horizonte de la segunda secularización (lo que algunos sociólogos llaman la secularización interna del cristianismo, en las diferentes denominaciones confesionales) y por el período precedente en que el cristianismo católico ha jugado un papel esencial en la confrontación de dos sistemas en un mundo bipolar y después ha mantenido ese papel de confrontación contra una cultura postmoderna que ha hecho del nihilismo antropológico su seña de identidad. La encíclica parece responder a ambos procesos, secularización y nihilismo, con una proposición positiva de la experiencia cristiana como preámbulo para indicar el camino de acceso al misterio cristiano de Dios.

En esta colaboración ${ }^{5}$ no propondré, naturalmente, una lectura completa de la encíclica, sino de los tres aspectos más significativos de su segunda parte: la centralidad del servicio de la caridad como tarea constitutiva de la Iglesia; el concepto de justicia en relación con el amor y la subsiguiente reflexión sobre el carácter autónomo de la política, aunque referenciada a la dimensión ética y espiritual; y, por último, la rica elaboración doctrinal sobre el servicio eclesial de la caridad, en particular sobre el voluntariado cristiano.

Antes de pasar a la exposición de estas tres cuestiones, que serán el objeto del trabajo, presento un breve apunte que se asome al contenido de la primera parte de la encíclica, titulada "La unidad del amor en la creación y en la historia de la salvación", que ofrece una reflexión filosófico-teológica

5 Para la que me he servido, en parte, de unas notas para el coloquio sobre la encíclica organizado por el Centro Pedro Arrupe de Sevilla, moderado por su director, padre Luis Aparicio (9-III-2006), en el que participaron doña Rosa M ${ }^{\mathrm{a}}$ Cobos Gavala, profesora de Derecho Procesal en la Universidad de Sevilla, y el autor de este texto. 
sobre el amor en sus constitutivas dimensiones, éros y ágapê.

El Papa hace una valoración extraordinariamente positiva de la dimensión erótica del amor. El amor erótico expresa la diferencia sexual (hombre-mujer) antropológica esencial (DCE 11:1). Al mismo tiempo es una dimensión común al hombre y a Dios; en el hombre, el amor erótico precisa de disciplina, purificación y maduración para no perder su dignidad y grandeza originarias, y no convertirse en una mercancía despersonalizada; el amor erótico es también una expresión máximamente significativa del amor de donación de Dios a la humanidad, del amor erótico de Dios, que atrae al amor humano a ser amor de oblación, de entrega, a ser ágapê. Ambas dimensiones, cada una constitutiva del amor humano en plenitud, reclaman no ser vividas separadamente una de la otra, aunque sean consideradas en su entidad propia; ambas dimensiones pueden deteriorarse en cada persona y en su progreso social, pero ambas pueden desarrollar en plenitud la naturaleza humana y social y convertirse, por así decirlo, en mandato, porque antes han sido un don entregado a los hombres.

El amor de Dios se expresa plenamente en la palabra griega ágapê, con que el nuevo testamento designa la novedad radical del amor de Dios, realizado simbólica y plenamente en la Eucaristía. Ésta, por fundarse en la relación dialogal, tiene un intrínseco carácter social y es parábola de la lucha cristiana por la justicia:

la "mística" del Sacramento tiene un carácter social, porque en la comunión sacramental yo quedo unido al Señor como todos los demás que comulgan: «El pan es uno, $y$ así nosotros, aunque somos muchos, formamos un solo cuerpo, porque comemos todos del mismo pan", dice san Pablo (1 Co 10:17). La unión con Cristo es al mismo tiempo unión con todos los demás a los que él se entrega. No puedo tener a Cristo sólo para mí; únicamente puedo pertenecerle en unión con todos los que son suyos o lo serán (DCE 14).

El amor cristiano (ágapê) funda la existencia cristiana, que surge de la unidad radical entre amor de Dios y amor a los hombres y mujeres. El precepto del amor puede existir sólo desde el don recibido del amor, el ágapê.

Se entiende, pues, que el ágapê se haya convertido también en un nombre de la Eucaristía: en ella el ágapê de Dios nos llega corporalmente para seguir actuando en nosotros y por nosotros. (...) fe, culto y éthos se compenetran recíprocamente como una sola realidad, que se configura en el encuentro con el ágapê de Dios. Así, la contraposición usual entre culto y ética simplemente desaparece. En el «culto» mismo, en la comunión eucarística, está incluido a la vez el ser amados y el amar a los otros. Una Eucaristía que no comporte un ejercicio práctico del amor es fragmentaria en sí misma (...) el "mandamiento» del amor es posible sólo porque no es una mera exigencia: el amor puede ser «mandado» porque antes es dado (DCE 14). 
Este amor a los hombres y mujeres se hizo en el evangelio de Jesús expansivo, universal, ${ }^{6}$ pero permanece concreto, pues el amor al prójimo no se reduce a una actitud genérica y abstracta, poco exigente en sí misma (DCE 15), sino que implica un compromiso. De ahí surge un deber de interpretación práctica de la Iglesia sobre la relación entre lejanía y proximidad y de esas consideraciones surge la segunda parte de la encíclica, titulada El ejercicio del amor por parte de la Iglesia como «comunidad de amor», que paso a presentar con más detalle?

\section{El servicio de la caridad, tarea constitutiva de la Iglesia (nn 19-25)}

La comunidad eclesial ha de ser, en el mundo, testigo del amor del Padre, que quiere hacer de la humanidad, en su Hijo, una sola familia. Toda la actividad de la Iglesia es la expresión de un amor que busca el bien integral del ser humano. Este bien integral se realiza a través de la evangelización y de la promoción humana en diversos ámbitos de la actividad humana. El servicio de la caridad (DCE 19:2), el servicio al amor que busca el bien integral, es el centro de la segunda parte de la encíclica. ${ }^{8}$

La primera afirmación que interesa subrayar, aunque no es nueva en el pensamiento social cristiano, es el carácter esencialmente constitutivo del servicio de la caridad en la vida, naturaleza y misión de la Iglesia. Benito XVI se refiere a la experiencia fundante descrita en el libro de los orígenes cristianos:

6 DCE 15, con referencia a las parábolas del buen samaritano (Lc 10:25-37) y del juicio final (Mt 25:31-46).

7 Algunos comentarios interesantes que he utilizado, de entre los aparecidos hasta el momento, son los siguientes: [EDITORIALE] (2006), “"Dio è amore» e la Chiesa è "servizio d'amore»": La Civiltà Cattolica, I (quad. 3735), 213-222; Luis GonzÁlez-CARvajal SAntABárbara (2006), "Un Papa que entiende de amores. La encíclica "Deus caritas est" de Benito XVI": Vida Nueva, nº 2524 (24-VI-2006), pp. 24-30; James Hanwey (2006), "Le magis de l'amour": Projet, no 292, 44-47; Julio Luis MarTíNez (2006), " "Deus caritas est»: el primado del amor en la moral”: Sal Terrae 94, 413-433; Rafael M. SANz DE Diego (2006), "Deus caritas est: un canto al amor total": Razón y Fe, 253, 199-207, y Bartolomeo Sorge (2006), "La "carità sociale" nell'enciclica di Benedetto XVI": Aggiornamenti Sociali, 57, 281-286; Denis Vı́́Not (2006), "Charité et action sociale": Projet, no 292, 42-44. Es interesante también la introducción y el comentario de Angelo Scola (2006) a una edición italiana, Siena 2006, Cantagalli, 166 pp.

8 Parece que el Papa aprovechó unas notas de su predecesor para una encíclica sobre la caridad. 
Lucas nos relata esto ${ }^{9}$ relacionándolo con una especie de definición de la Iglesia, entre cuyos elementos constitutivos enumera la adhesión a la «enseñanza de los Apóstoles», a la "comunión" (koinonia), a la "fracción del pan" y a la "oración" (cf. Hch. 2:42). La "comunión»(koinonia), mencionada inicialmente sin especificar, se concreta después en los versículos antes citados: consiste precisamente en que los creyentes tienen todo en común y en que, entre ellos, ya no hay diferencia entre ricos y pobres (cf. también Hch. 4:32-37) (DCE 20).

Este ejercicio de la koinonia conlleva enseguida la organización de un servicio que no debe limitarse a ser meramente técnico (DCE 21), sino lleno de espíritu y sabiduría, que hay que ejercer como servicio social concreto, en el que se realiza un cometido esencial de la Iglesia (DCE 21). Por esta nueva dimensión instaurada en la comunidad cristiana, "la "diaconía" ${ }^{10}$-el servicio del amor al prójimo ejercido comunitariamente y de modo orgánico- quedó instaurada en la estructura fundamental de la Iglesia" (DCE 21), por lo que a partir de entonces la diaconía pertenece a la esencia de la Iglesia tanto como los sacramentos y la palabra (DCE 22); por ello, probablemente ya en la primera Iglesia, era "el único aspecto" del cristianismo que impresionaba a muchos. Dos notas caracterizan, según el Papa, este servicio de la caridad:

a) El amor al prójimo (caritas-ágapê) supera los confines cristianos: la parábola del buen samaritano muestra la universalidad del amor que se dirige hacia el necesitado, quienquiera que sea, encontrado "casualmente» (cf. Lc 10: 31). ${ }^{11}$ El buen samaritano es el criterio universal, formal y a priori, para la interpretación del servicio eclesial de la caridad.

b) La naturaleza íntima de la Iglesia se expresa en una triple tarea: anuncio de la Palabra (kerygma-martyria), celebración sacramental (leiturgia) y servicio de la caridad (diakonia). Estas tres dimensiones o tareas no pueden separarse una de otra, por lo que, para la Iglesia, la caridad no es una simple asistencia social, sino que pertenece a su naturaleza y es manifestación irrenunciable de su propia esencia (DCE 25).

9 El autor se refiere al resumen de la vida de los primeros cristianos, Hch 2:44-45, citado anteriormente.

10 La actividad caritativa de la Iglesia, DCE 24.

11 Cfr. DCE 25, entre comillas en el original la palabra "causalmente". 


\section{La justicia, realidad temporal autónoma y referenciada (nn 26-29)}

En la encíclica, el Papa aborda la cuestión social. Podemos decir, con Bartolomeo Sorge, que ésta "es también una encíclica social". ${ }^{12}$ Expondré, al principio, el enunciado de las tres afirmaciones centrales que se engarzan en le encíclica, para analizar después cada una de ellas.

Las afirmaciones centrales pueden formularse sintéticamente así: en primer lugar, el Estado debe buscar un orden social justo, en que todos y cada uno tengan parte en los bienes sociales; en segundo lugar, la doctrina social es una indicación fundamental para proponer, más allá de los límites eclesiales, orientaciones para un orden social justo; en tercer lugar, la Iglesia no puede sustituir al Estado ni debe emprender la empresa política de una sociedad más justa, pero tampoco debe quedarse al margen de la lucha por la justicia.

La encíclica concibe pues que la caridad, en cuanto puesta en práctica del amor, es una tarea de la Iglesia (DCE 20) que integra dos tareas mediatas y una inmediata: en las tres se despliega la acción de la Iglesia en relación con la justicia. Las dos tareas mediatas de la Iglesia son su relación con el Estado (DCE 29:1) y la acción de los cristianos seglares (DCE 29:2); la tarea inmediata (opus proprium, 29:3) que corresponde a la Iglesia, según la encíclica, es la caridad organizada (DCE 31).

3.1. El Estado debe buscar un orden social justo en que todos y cada uno tengan parte en los bienes sociales. Ésta es la tarea central de la política (DCE 28:1)

\subsubsection{Tesis primera}

La encíclica afirma con claridad que "una norma fundamental del Estado debe ser perseguir la justicia", pues el objetivo de un orden social justo es la garantía para los ciudadanos que pueden participar "de los bienes comunes" (DCE 26); la encíclica parte de la "autorresponsabilidad racional de la política", ${ }^{13}$ puesto que el establecimiento de estructuras justas pertenece a la esfera de la política. Esto lo dice Benito XVI después de recoger algunos

12 Cfr. B. Sorge (2006), art. cit., p. 281. Las cursivas son mías.

13 B. Sorge (2006), 285; cfr. DCE 29:1. 
rasgos del debate desarrollado entre justicia y caridad, entre mediación política y mediación eclesial, en el siglo XIX. ${ }^{14}$

Parece pues que el Papa apunta a la existencia de un límite en la labor de caridad: el límite que le marca la acción de la política en pro de una transformación estructural. Esto no es novedad, puesto que lo "ha subrayado también la doctrina cristiana sobre el Estado y la doctrina social de la Iglesia”. Parece, aunque no esté dicho explícitamente, que el Papa piense que la pretensión de una política de beneficencia de la sociedad civil, de un llamado "capitalismo compasivo", que compensara los errores e imprevisiones del neoliberalismo, sin regulación pública ninguna, pueda ser un riesgo para la correcta propuesta de la solidaridad social eclesial en la sociedad del bienestar. ${ }^{15} \mathrm{El}$ pensamiento social cristiano afirma, como logro indiscutible, el papel del Estado al servicio de la justicia: "Es cierto que una norma fundamental del Estado debe ser perseguir la justicia y que el objetivo de un orden social justo es garantizar a cada uno (...) su parte de los bienes comunes" (DCE 26). No deben plantearse recortes a ese papel del Estado, que es irrenunciable, aunque el Estado no sea exclusivamente competente para definir el contenido de la justicia:

La justicia es el objeto y, por tanto, también la medida intrínseca de toda política. La política es más que una simple técnica para determinar los ordenamientos públicos: su origen y su meta están precisamente en la justicia, y ésta es de naturaleza ética. Así, pues, el Estado se encuentra inevitablemente de hecho ante la cuestión de cómo realizar la justicia aquí y ahora (DCE 28:1).

14 Las obras de caridad -la limosna-serían en realidad un modo para que los ricos eludan la instauración de la justicia y acallen su conciencia, conservando su propia posición social y despojando a los pobres de sus derechos. En vez de contribuir con obras aisladas de caridad a mantener las condiciones existentes, haría falta crear un orden justo, en el que todos reciban su parte de los bienes del mundo y, por lo tanto, no necesiten ya las obras de caridad. Se debe reconocer que en esta argumentación hay algo de verdad, pero también bastantes errores (DCE 26). Benito XVI reconoce que en esta argumentación hay algo de verdad (DCE 26).

15 Ésta sería la pretensión de una ideología del capitalismo que asume el rostro de una religión de salvación: "usar" a las religiones existentes, entre ellas el cristianismo, como "asistentes" del sistema. Esta tipo de ideología capitalista exige la adhesión radical, total, "religiosa", a la "religión" en la se ha convertido la sociedad de mercado (es decir, la extensión invasiva de la lógica de la economía de mercado a todas las relaciones sociales, regulando por la lógica del intercambio de interés todas las realidades), compensaría compasivamente los "defectos" del sistema. A esta forma religiosa de capitalismo se refería críticamente Petrella, el fundador-presidente del Grupo de Lisboa y profesor de Lovaina, como la "santísima trinidad" (PRIDESLIB): pri(vatización)-des(regulación)-lib(eralización); cfr. Riccardo PETRELLA (1996), "El credo de fin de siglo": El Ciervo. Revista mensual de pensamiento y cultura (julio-agosto), pp. $4-7$. 
Pero tampoco deben plantearse oposiciones excluyentes entre caridad y justicia; es decir, la encíclica rechaza la objeción contra la actividad caritativa de la Iglesia, desarrollada (...) sobre todo por el pensamiento marxista, que contrapondría obras de caridad (innecesarias e ideológicamente interesadas) a obras de justicia. La afirmación de la necesidad política de "crear un orden justo, en el que todos reciban su parte de los bienes del mundo y, por lo tanto, no necesiten ya las obras de caridad" no puede ser absolutizada; si hay algo de verdad en esa argumentación (crítica, sobre todo marxista, aunque no proceda sólo de esa corriente), habrá que estar atentos a que no se reproduzcan los excesos señalados; pero también, si hubiere bastantes errores en esta argumentación, habría que estar atentos a no dejarse envolver por los mismos.

En cualquier caso, acierta a formular el Papa: la Iglesia no pretende tener un poder sobre el Estado, ni quiere imponer a los que no comparten la fe sus propias perspectivas y modos de comportamiento (DCE 28:4 y 5). Benito XVI afirma taxativamente que no es tarea de la Iglesia el que ella misma haga valer políticamente esta doctrina (DCE 28:5). Todo ello nos lleva a la distinción de ámbitos y a la complementariedad sin exclusiones entre acciones política y eclesial.

3.1.2. Tesis complementaria: La autonomía de las realidades temporales ha de entenderse a partir de los principios hermenéuticos de subsidiariedad y de cambio histórico

En primer lugar, es propio de la estructura fundamental del cristianismo la distinción entre Estado e Iglesia, a partir del principio, reconocido por el Concilio Vaticano II, de la autonomía de las realidades temporales; el fin del Estado ha de seguir siendo considerado, a partir de estos dos principios hermenéuticos: el de subsidiariedad y el del cambio histórico que supuso para el papel del Estado la formación de la sociedad industrial.

La encíclica recoge el principio conciliar de autonomía de las realidades temporales. Nuestros contemporáneos parecen temer que "por una excesivamente estrecha vinculación entre la actividad humana y la religión, sufra trabas la autonomía del hombre, de la sociedad o de la ciencia". ${ }^{16}$ Por ello parece oportuno recordar lo que formuló la constitución conciliar Gaudium

16 Concilio Vaticano II, Constitución pastoral Gaudium et Spes (7-XII-1965) 36:1. 
et Spes, al hablar de la justa autonomía de la realidad terrena:

autonomía de la realidad (...) quiere decir que las cosas creadas y la sociedad misma gozan de propias leyes y valores, que el hombre ha de descubrir, emplear y ordenar poco a poco. ${ }^{17}$

Para el concilio esta exigencia de autonomía es absolutamente legítima, puesto que no sólo la reclaman los hombres de nuestro tiempo, sino que "responde a la voluntad del Creador", pero también recuerda el concilio que la realidad creada no es independiente de Dios y que los hombres no pueden usarla "sin referencia al Creador", puesto que "la criatura sin el Creador desaparece".

Podemos referir esta autonomía de las realidades temporales a un principio hermenéutico que, continuamente releído en la tradición del pensamiento social cristiano, es el principio de subsidiariedad. En sus formulaciones más clásicas este principio es bien conocido. Me detendré en la concepción de Juan Pablo II (1991), aunque recordaré antes dos momentos importantes de elaboración de dicho principio: el original de Pío XI y las precisiones posteriores de Pablo VI.

En 1931 Pío XI introdujo en la filosofía social la conceptualización de "aquel gravísimo principio inamovible e inmutable", por el que hay que aceptar que, de la misma manera que "no se puede quitar a los individuos y dar a la comunidad lo que ellos pueden realizar con su propio esfuerzo e industria, así tampoco es justo, constituyendo un grave perjuicio y perturbación del recto orden, quitar a las comunidades menores e inferiores lo que ellas pueden hacer y proporcionar y dárselo a una sociedad mayor y más elevada". ${ }^{18}$ Este principio que irá conociendo ulteriores precisiones por la complejidad creciente de las realizaciones sociales, se mantiene en cuanto toda acción de la sociedad "debe prestar ayuda a los miembros del cuerpo social, pero no destruirlos y absorberlos". ${ }^{19}$ Aunque Pío XI no usara esa palabra entonces, esta formulación tradicionalmente ha sido conocida como principio de subsidiariedad. ${ }^{20}$

17 Ibid.

18 Pío XI (1931), Quadragesimo anno 79.

19 Ibid.

20 Desde el Tratado de Maastricht el concepto de subsidiaridad figura incluso en la legislación europea. Así el Tratado por el que se establece una Constitución para Europa, dice "en virtud del principio [de subsidiaridad], en los ámbitos que no sean de su competencia exclusiva, la 
Con la creciente complejidad de las estructuras sociales en los años 60 , Juan XXIII reconocía, en la economía, nuevos e interesantes matices del principio de subsidiariedad, como después haría Pablo VI en la política. ${ }^{21}$ El poder político constituye el vínculo natural y necesario para asegurar la cohesión del cuerpo social y está, o debe estar, al servicio de la realización del bien común, al servicio de la creación de aquellas condiciones requeridas para conseguir el bien auténtico y completo de toda persona, incluido su destino espiritual y tiene "la responsabilidad última" de la cooperación al servicio del bien común. No quita, pues, a la persona ni a los cuerpos intermedios su responsabilidad social. ${ }^{22}$

En términos más contemporáneos ha sido Juan Pablo II quien ha vuelto a aclarar esta tensión entre el deber de justicia del Estado y el derecho de libertad de las instancias sociales, promoviendo una concepción de complementariedad entre ambos ámbitos. La redacción, en la encíclica conmemorativa del centenario de la Rerum novarum, es compleja, como era habitual en él.

En el texto me parece oportuno destacar tres afirmaciones centrales. En primer lugar, la actividad de la economía de mercado no puede desenvolverse en medio de un vacío institucional, jurídico y político, por lo que el Estado ha de vigilar y encauzar el ejercicio de los derechos humanos en ese ámbito, pero sin asumir la primera responsabilidad, que es de las personas y de los diversos grupos y asociaciones de la sociedad civil. Por otra parte, el pensamiento social cristiano reclama la primacía de la sociedad civil, pero sin aceptar la posición neoliberal de ausencia de toda forma de regulación social, pues como afirma categóricamente Juan Pablo II esta iniciativa social primordial "no significa que el Estado no tenga ninguna competencia en este ámbito, como han afirmado quienes propugnan la ausencia de reglas

Unión intervendrá sólo en el caso de que, y en la medida en que, los objetivos de la acción pretendida no puedan ser alcanzados de manera suficiente por los Estados miembros, ni a nivel central ni a nivel regional o local, sino que puedan alcanzarse mejor, debido a la dimensión o a los efectos de la acción pretendida, a escala de la Unión" (TCE I-11:3). El Estatuto de Cataluña (2006) afirma: "Los poderes públicos están al servicio del interés general y de los derechos de la ciudadanía, con respeto al principio de subsidiariedad" (preámbulo).

21 Juan XXIII, Mater et magistra (1961), nn 53 y 117 y Pacem in terris (1963), nn 140-141. También la constitución conciliar Gaudium et spes (1965), nn 74-76, se refirió a esta cuestión.

22 Pablo VI (1971), Octogesima adveniens, n 46, citando los documentos Quadragesimo anno, Mater et Magistra y Gaudium et Spes, en los números que he indicado en notas anteriores. 
en la esfera económica". Por último, la complementariedad que afirma una presencia activa del Estado ("en cierto modo un Estado de índole nueva: el "Estado del bienestar»"), junto al respeto del principio de subsidiariedad. La definición que ofrece Juan Pablo II es continuadora, pero enriquecida, en relación con la de Pío XI:

Una estructura social de orden superior no debe interferir en la vida interna de un grupo social de orden inferior, privándola de sus competencias, sino que más bien debe sostenerla en caso de necesidad y ayudarla a coordinar su acción con la de los demás componentes sociales, con miras al bien común. (...) un cierto tipo de necesidades requiere con frecuencia una respuesta que sea no sólo material, sino que sepa descubrir su exigencia humana más profunda. ${ }^{23}$

Nos ha parecido necesario desarrollar los antecedentes de este concepto de subsidiariedad, porque mucho de lo que dice Benito XVI en su texto supone la adecuada, compleja y matizada formulación de este principio de subsidiariedad. Como comentaremos en la tesis tercera, en esta encíclica Benito XVI afirma taxativamente que la justicia es (...) la medida intrínseca de toda política (DCE 28:3).

Esta autonomía, a nuestro juicio, viene hoy reformulada desde un hecho mayor al que hemos aludido y que, con palabras de Benito XVI, podemos expresar de la siguiente forma: cada generación debe afrontar de nuevo la tarea fundamental de la construcción de un orden social y estatal justo. ${ }^{24} \mathrm{La}$ encíclica hace una doble alusión. Por un lado apunta que la industria moderna desbarató las viejas estructuras sociales y provocó un cambio radical en la configuración de la sociedad. En ella la relación entre el capital y el trabajo se convirtió en cuestión decisiva, puesto que la concentración del poder en manos de unos pocos, privaba a las masas obreras de unos derechos contra la cual había que rebelarse (DCE 26). No obstante, como constata el documento, también el sueño del marxismo se ha desvanecido (DCE 27), dejando una difícil situación que Benito XVI no analiza, pero a cuya causa alude: la globalización de la economía. Probablemente para comprender el mundo de hoy nos haga falta un nuevo paradigma ${ }^{25}$, que viene concibiéndose como paradigma postsocial o cultural. Parece que en este paradigma se sitúan las reflexiones de la

23 Juan Pablo II (1991), Centesimus annus, n 48.

24 DCE 28.5 .

25 Utilizo deliberadamente el título y subtítulo de una reciente obra que está llamada a abrir una reflexión interesante. Me parece que el pensamiento social cristiano habrá de pensarse a partir de este paradigma cultural del que habla Alain TouraINe (2005), Un nuevo paradigma para comprender el mundo de hoy, Barcelona, Paidós. 
encíclica, sobre todo las recogidas entre los números 30 y 39. En esta difícil situación es lógico que esta generación afronte de nuevo la tarea fundamental de la construcción de un orden social y estatal justo. Sin embargo, la novedad permanente que el horizonte histórico de la actualidad supone para toda acción política expresa un criterio fundamental de interpretación.

3.2. La doctrina social es una indicación fundamental para proponer, más allá de los límites eclesiales, orientaciones para un diálogo con todos (DCE 28)

\subsubsection{Tesis segunda}

Aunque no sea estrictamente sólo un documento de doctrina social, DCE presenta con fuerza algunas cuestiones propias y nucleares de la enseñanza social cristiana. Entre estas, se pueden subrayar tres: la pervivencia y una nueva aclaración del estatuto de la doctrina social, la reflexión sobre los límites de la justicia y, por último, el respeto a la separación de ámbitos, religioso y político.

a) La pervivencia de la doctrina social de la Iglesia. La doctrina social se ha ido desarrollando a partir del encuentro de la Iglesia con la problemática de la sociedad industrial (las "cosas nuevas" según la expresión de León XIII). Después de los años postconciliares y de los silencios, por un lado, y nuevos enfoques de Pablo VI, por otro, quien prefería entonces hablar de enseñanzas sociales, más relacionadas con las ciencias sociales y con la pluralidad de situaciones eclesiales y sociopolíticas y, por tanto, menos doctrinales, con Juan Pablo II pareció que quedó fuera de discusión, para el magisterio, la conveniencia de la doctrina social como reflexión y orientación eclesial; ésta quedó re-consagrada no sólo como concepto, sino como expresión adecuada. En ambos papas, según Ildefonso Camacho, se fue perfilando "una concepción más rica de la doctrina social". ${ }^{26}$

La encíclica DCE menciona la expresión doctrina social, al menos en seis ocasiones; no deja de ser significativo que el documento fuese presentado por "tres tenores" de la curia vaticana: el primero, el cardenal presidente del pontificio consejo Iustitia et Pax (Renato R. Martino), el segundo, el sucesor

26 Cfr. Ildefonso CAMACHo LARAÑA (2000), Doctrina social de la Iglesia. Quince claves para su comprensión, Desclée de Brouwer, Bilbao, p. 32. 
de J. Ratzinger como prefecto de la Congregación para la Doctrina de la Fe (William J. Levada) y, en tercer lugar, el presidente del pontificio consejo Cor Unum (Paul J. Cordes) ${ }^{27}$. Dos de ellos, Martino y Cordes, están directamente relacionados, por oficio, con el desarrollo de la doctrina social.

La doctrina social de la Iglesia se presenta en esta encíclica como indicación fundamental para proponer, en diálogo con todos, orientaciones más allá de los límites eclesiales (DCE 27). Tres son los elementos de esta definición: el proyecto formal (orientaciones o indicación fundamental), el procedimiento (propuesta para el diálogo) y el ámbito (transeclesialidad).

i) El proyecto formal de la encíclica consiste en ofrecer una indicación fundamental, es decir, el intento de orientar o guiar a los hombres para que "ellos mismos den una respuesta" a su vocación de construcción responsable de la sociedad. ${ }^{28}$ Según Benito XVI la Iglesia tiene una propuesta indicativa que hacer, es decir una propuesta que marca un sentido, pero que no resuelve la totalidad del proceso porque éste corresponde a la sociedad en su conjunto. La Iglesia no tiene soluciones técnicas que ofrecer, ni propone sistemas o programas económicos o políticos, ni siquiera manifiesta preferencias por unos o por otros ${ }^{29}$, pero "tiene una palabra que decir" 30 que pertenece a su misión evangelizadora, es decir que surge de su núcleo fundamental, como viene subrayando el magisterio desde el concilio Vaticano II. A esta dimensión no es ajena la vocación personal de los creyentes pues, como dijo este concilio "todos los fieles (...) están llamados a la plenitud de la vida cristiana y a la perfección de la caridad y esta santidad suscita un nivel de vida más humano incluso en la sociedad terrena", ${ }^{31}$ lo que luego fue ratificado por el sínodo de los obispos de 1971 en su documento La justicia en el mundo (1971) ${ }^{32}$ y por

27 En su intervención Cordes hacía constar que "la doctrina social de la Iglesia y la teología de la caridad se reclaman". Vid. www.vatican.va/news_services/bulletin/news, consultada el 25-I-2006, conferenza stampa, (12:00 hs. a.m.), $\mathrm{n}^{\mathrm{o}} 8$.

28 Juan Pablo II (1987), Sollicitudo rei socialis, n. 1.

29 Juan Pablo II (1987), Sollicitudo rei socialis, n. 41:1.

30 Ibid, n. 41:4.

31 Constitución dogmática Lumen gentium, n. 40:2, 1964.

32 Los obispos reunidos en aquel sínodo tuvieron conciencia de las injusticias internacionales y formularon una afirmación nueva: La acción a favor de la justicia y la participación en la transformación del mundo se nos presenta claramente como una dimensión constitutiva de la predicación del evangelio, es decir, de la misión de la Iglesia para la redención del género humano y la liberación de toda situación opresiva (Introducción al documento final). 
Pablo VI en la exhortación post-sinodal Evangelii nuntiandi (1974) ${ }^{33}$.

Juan Pablo II, recuperando la expresión "doctrina social", reclamó una categoría propia para la misma como parte de la teología moral, es decir, como "la cuidadosa formulación de una atenta reflexión", hecha desde la fe y la tradición eclesial, sobre la realidad de la vida humana, tanto de cada sociedad como del contexto internacional, la interpretación de esas realidades complejas desde el evangelio y la orientación de la conducta cristiana ${ }^{34}$ Este conjunto de reflexión, interpretación y orientación constituyen una indicación para los creyentes ${ }^{35}$, pero para Benito XVI es también importante, quizá con más fuerza que para Pablo VI y Juan Pablo II, que esta indicación fundamental "propone orientaciones válidas mucho más allá de sus confines" (DCE 27) "en la difícil situación en la que nos encontramos hoy, a causa también de la globalización de la economía" (DCE 27). El Papa no pretende sólo que la doctrina social de la Iglesia sea una parte de la teología moral (aunque no lo niegue, obviamente), sino que ofrezca indicaciones extraeclesiales, en diálogo con todos los que se preocupan seriamente por el hombre y su mundo (DCE 27).

Observamos un intento de desconfesionalización parcial de la doctrina social de la Iglesia y de una cierta recuperación de su dimensión filosófica. En este siglo éste ha sido un tema debatido largamente. Tres etapas se han sucedido en la formulación católica de la doctrina social: la metafísica que comprende de León XIII a Pío XII (1878-1958), la histórico-social en torno al concilio y sus papas (1958-1978) y la teológica, representada por

33 Pablo VI (1974), Evangelii nuntiandi, nn 31 y 33: (...) no es posible aceptar «que la obra de evangelización pueda y deba olvidar las cuestiones extremadamente graves, tan agitadas hoy día, que atañen a la justicia, a la liberación, al desarrollo y a la paz en el mundo. Si esto ocurriera, sería ignorar la doctrina del evangelio acerca del amor, hacia el prójimo que sufre o padece necesidad»; aunque, pocas líneas más adelante, añadía: (...) quisimos subrayar en la misma alocución de la apertura del Sínodo "la necesidad de reafirmar claramente la finalidad específicamente religiosa de la evangelización. Esta última perdería su arzón de ser si se desviara del eje religioso que la dirige: ante todo el reino de Dios, en su sentido plenamente teológico»; esta exhortación apostólica fue posterior al sínodo de 1974; los dos párrafos citados hacen, a su vez remisión al discurso del Papa en la apertura de la tercera asamblea general del sínodo de los obispos (27-IX-1974).

34 Juan Pablo II (1987), Sollicitudo rei socialis, n. 41, párrafo 7.

35 CONGREGACIÓN PARA la DoctRINA DE LA FE (1986), Instrucción Libertatis conscientiae sobre libertad cristiana y liberación, n 72 (22-III-1986). En el mismo documento se hace referencia a Pablo VI (1971), Octogesima adveniens, n 4. 
Juan Pablo II (1978-2005). Con Benito XVI parece que se retorna a cierta pretensión filosófica, ${ }^{36}$ anunciada pero no desarrollada en la encíclica, cuando formula esta indicación fundamental. En el texto pontificio se menciona el Compendio de la doctrina social de la Iglesia ${ }^{37}$ con el que se pretende "exponer de manera sintética, pero exhaustiva, la enseñanza social de la Iglesia", con la doble finalidad de "sostener y animar la acción de los cristianos en el campo social".

ii) El procedimiento es el diálogo como propuesta. La encíclica presenta la enseñanza social como una propuesta no impuesta, sino ofrecida para el diálogo. Ciertamente no puede ser de otra forma, pues ésta es una guía para inspirar, en el ámbito individual y colectivo, los comportamientos y opciones que permitan mirar al futuro con confianza y esperanza, que está al servicio del "discernimiento moral y pastoral de los complejos acontecimientos que caracterizan nuestro tiempo" ${ }^{38}$ La encíclica insiste en que "en la difícil situación en la que nos encontramos hoy" las indicaciones de la doctrina social de la Iglesia se han de afrontar en diálogo con todos los que se preocupan seriamente por el hombre y su mundo (DCE 27).

Según Pablo VI, el diálogo era la orientación que había sido transmitida por la Iglesia desde León XIII, al hacer objeto de la enseñanza católica "los problemas de nuestro tiempo considerados a la luz de la palabra de Cristo", y la que debía caracterizar su ministerio como Papa ${ }^{39}$ Este diálogo llevó a expresar la enseñanza "en el lenguaje del hombre moderno", acercándose "lo más posible a la experiencia y a la comprensión del mundo contemporáneo", con vistas a la inserción del mensaje cristiano "en la corriente (...) de la tendencia de la humanidad tal cual hoy vive y se mueve sobre la haz de la tierra". ${ }^{40}$ Este diálogo tiene algunas características que conviene enume-

36 "La doctrina social de la Iglesia argumenta desde la razón y el derecho natural, es decir, a partir de lo que es conforme a la naturaleza de todo ser humano” (DCE 28:1).

37 "Así pues, cotejando situaciones y problemas nuevos cada vez, se ha ido desarrollando una doctrina social católica, que en 2004 ha sido presentada de modo orgánico en el Compendio de la doctrina social de la Iglesia, redactado por el Consejo Pontificio Iustitia et Pax" (DCE 27).

38 Compendio de la doctrina social de la Iglesia (2004), Introducción, n. 10.

39 Pablo VI (1964), Ecclesiam suam. Encíclica sobre los caminos que la Iglesia católica debe seguir en la actualidad para cumplir su misión, n 62.

40 Ibid. 
rar: excluye las actitudes de condena; es una tarea sin límites ni cálculos; actúa por las vías de la educación humana, de la persuasión interior, de la conversación común; supone y exige capacidad de comprensión común, que lleva a la claridad; evita la ofensa, la herida, el orgullo o los modos violentos; confía en la palabra humana y en la amistad; tiene en cuenta la prudencia y la adaptación a cada interlocutor, y a su sensibilidad. ${ }^{41}$

iii) La enseñanza social cristiana sobrepasa el ámbito eclesial. Ésta es la característica de la transeclesialidad, que define el alcance que esencialmente tiene la doctrina social. Para Benito XVI la preocupación social forma parte de la doctrina social de la Iglesia, que "propone orientaciones válidas mucho más allá de sus confines", llevando su interés más allá de los límites eclesiales. Aunque la encíclica se dirige al interior de la comunidad cristiana y es un documento de carácter teológico, precisamente por ello, tiene más importancia que la misma subraye que las indicaciones propuestas por la Iglesia miran más allá de la misma. También el citado Compendio se había propuesto "como ocasión de diálogo con todos aquellos que desean sinceramente el bien del hombre", ${ }^{42}$ proponiendo, de forma orgánica, unos principios que orienten para que "el discernimiento, el juicio y las opciones respondan a la realidad y para que la solidaridad y la esperanza puedan incidir también en las complejas situaciones actuales". 43

La encíclica, como el Compendio, se ofrece a los obispos católicos, a los miembros del pueblo de Dios, a las comunidades cristianas, para que puedan "analizar objetivamente las situaciones, clarificarlas a la luz de las palabras inmutables del Evangelio, recabar principios de reflexión, criterios de juicio y orientaciones para la acción", y a otros destinatarios, religiones y culturas incluidas, que manifiestan su disponibilidad "al diálogo" y desean urgentemente unir los propios esfuerzos para favorecer la justicia, la fraternidad, la paz y el crecimiento de la persona humana". ${ }^{44}$ Esta apertura de la encíclica coincide con el horizonte del Compendio como

41 Ibid., nn 63-75.

42 Pontificio Consejo "Justicia y Paz" (2004), Compendio de la doctrina social de la Iglesia, Roma, Libreria editrice vaticana, Introducción, n 10.

43 Pontificio Consejo "Justicia y Paz" (2004), Compendio..., cit, Introducción, n 9.

44 Pontificio Consejo “Justicia y Paz” (2004), Compendio..., cit, Introducción, nn 11 y 12. 
acto de servicio de la Iglesia a los hombres y mujeres de nuestro tiempo, a quienes ofrecer el patrimonio de su doctrina social, según el estilo de diálogo con que Dios mismo habla a los hombres como amigos. ${ }^{45}$

\subsubsection{Tesis complementaria}

Puesto que la justicia es el objeto y, por tanto, también la medida intrínseca de toda política, se produce un encuentro dialéctico entre la fe, que ha de desarrollar continuamente una labor de purificación de la razón, y la acción política porque su ceguera ética, que deriva de la preponderancia del interés $y$ del poder que la deslumbran, es un peligro que nunca se puede descartar totalmente.

El Estado se encuentra, según la encíclica, confrontado a la cuestión de cómo realizar la justicia aquí y ahora, pregunta que lleva a otra más de fondo, resoluble sólo desde la razón práctica: ¿qué es la justicia? En este punto, política y fe se encuentran (DCE 28), pues aunque

(...) la naturaleza específica de la fe es la relación con el Dios vivo (...) al mismo tiempo, es una fuerza purificadora para la razón misma (...). La fe permite a la razón desempeñar del mejor modo su cometido y ver más claramente lo que le es propio (DCE 28:3).

En la encíclica el Papa simplemente da por supuesta la afirmación de que la doctrina social no pretende imponer a los que no comparten su fe [cristiana] sus propias perspectivas y modos de comportamiento. Desea simplemente contribuir a la purificación de la razón ${ }^{46}$ (DCE 28:3) y sugiere dos contribuciones de la fe a la purificación de la razón: el reconocimiento por la razón teórica (para que lo que es justo, aquí y ahora, pueda ser reconocido) y la puesta en práctica. La fe ayuda a la razón "a ser mejor ella misma" (DCE 28:3). Para entender el cómo de esta ayuda me permito la referencia a una reciente intervención pública del aún cardenal Ratzinger.

En un reciente debate sostenido con Jürgen Habermas, ${ }^{47}$ J. Ratzinger

45 Pontificio Consejo "Justicia y Paz" (2004), Compendio..., cit, Introducción, n 13, donde hace referencia a la constitución dogmática Dei Verbum, (1965) n 2 y a algunos textos de la Escritura.

46 La expresión "purificación de la razón", o equivalente, es usada tres veces en la encíclica: nn 28:3, 28:4 y 28:5.

47 Cfr. Jürgen Habermas y Joseph Ratzinger (2005), "Diálogo entre la razón y la fe", en La Vanguardia 1-V-2005, pp. 26-29, también "Les fondements pré-politiques de l'État démocrate”, en 
afirmaba que es "tarea de la política someter el poder al control de la ley a fin de garantizar que se haga un uso razonable de él". ${ }^{48} \mathrm{Si}$ "el ser humano" no quiere quedar reducido a su condición de producto de sí mismo, "debe abrir sus opciones a un fundamento que esté más allá de él”. ${ }^{49}$ Ésta fue, y ha sido hasta hace poco tiempo, la tradición europea de referencia al derecho natural:

El derecho natural ha seguido siendo la figura de argumentación con la que se apela a la razón común en el diálogo con la sociedad secular y con otras comunidades religiosas y se buscan los fundamentos para un entendimiento en torno a los principios éticos del derecho en una sociedad secular pluralista. ${ }^{50}$

Aunque, según Ratzinger, "por desgracia el derecho natural ha dejado de ser una herramienta fiable", ${ }^{1}$ de él aún nos quedan, como último elemento, los derechos humanos, que

...no son comprensibles si no se acepta previamente que el hombre por sí mismo, simplemente por su pertenencia a la especie humana, es sujeto de derechos, y su existencia misma es portadora de valores y normas, que pueden encontrarse, pero no inventarse. ${ }^{52}$

En este momento de aporía de occidente, en el que sus dos grandes creaciones culturales, la fe cristiana y la racionalidad secular, se auto-perciben y son percibidas como realidades no universales, la situación europea aparece marcada "por la fatiga del racionalismo", es decir por la incapacidad para acceder a todas las dimensiones de la racionalidad y por la conciencia creciente de los propios límites de la misma. Por ello, no existiendo una definición del mundo compartida por todos y que pueda servir de soporte a todas las culturas, una ética presuntamente global tampoco pasa de ser una mera abstracción. En esta aporía, la fe cristiana aporta un papel. De la misma manera que la razón puede servir para contrarrestar las patologías de

Esprit (julio 2004). Se trata de un coloquio entre ambos celebrado el 19 de enero de 2004 en la Academia Católica de Munich. He analizado esta problemática, aunque desde otra perspectiva, en José María MARGENAT (2006), "Laicidad y creencia religiosa en una sociedad democrática", en Lydia FEITo (ed.) (2006), Encuentros y tensiones entre ideologías, Madrid, Universidad Pontificia Comillas y Asociación interdisciplinar "José de Acosta", 77-101.

48 Ibid., p. 28.

49 Cursiva mía.

50 Ibid., p. 29.

51 Ibid., p. 29.

52 Ibid., p. 29. 
la fe religiosa, la razón está necesitada de controlar sus propias patologías, incluso de aquellas de las que no fuera consciente. La razón "debe (...) ser consciente de sus límites y aprender a prestar oído a las grandes tradiciones religiosas de la humanidad". No pretendía afirmar un inmediato retorno a la fe, sino algo más modesto: una relación correlativa entre razón y fe, razón y religión "llamadas a depurarse y redimirse recíprocamente, que se necesitan mutuamente y que deben reconocerlo ante el otro lado". 53

En la mencionada ocasión de 2005, Ratzinger se inclinaba por sustituir la referencia al derecho natural por una referencia a los derechos humanos, pero en la encíclica vuelve a argumentar, como había hecho el documento, desde la razón y el derecho natural, es decir, a partir de lo que es conforme a la naturaleza de todo ser humano. ${ }^{54}$

Aunque sabe que no se trata de hacer valer políticamente esta doctrina, la Iglesia no renuncia a formar las conciencias en la política y a que crezca la percepción de las verdaderas exigencias de la justicia, aun cuando una actuación justa puede entrar en contraste con intereses personales. ${ }^{55}$

(....) la construcción de un orden social y estatal justo, mediante el cual se da a cada uno lo que le corresponde, es una tarea fundamental que (...) no puede ser un cometido inmediato de la Iglesia. Pero, como al mismo tiempo es una tarea humana primaria, la Iglesia tiene el deber de ofrecer, mediante la purificación de la razón y la formación ética, su contribución específica, para que las exigencias de la justicia sean comprensibles y políticamente realizables (DCE 28).

Refiriéndose a la distinción entre el Estado y la Iglesia, a la autonomía de las realidades temporales, dice que "la Iglesia no sólo reconoce y respeta esta distinción y autonomía, sino que también se alegra de ella”, y en el ejercicio

53 Ibid., p. 29; como afirma Bartolomeo Sorge, "la purificación de la razón mira a la justicia", cfr. B. SORGE (2006), art. cit, p. 282.

54 Pues, como dijo, a los representantes de la Santa Sede ante los organismos internacionales (18-III-2006): "Las relaciones entre los Estados y en los Estados son justas en la medida en que respetan la verdad. (...) la verdad tiene fuerza en sí misma y no en el número de consensos que recibe". Consulta en www.vatican.va

55 El Papa dijo en su discurso a los participantes en la reunión promovida por el Partido Popular Europeo (30-III-2006): “...cuando las Iglesias o las comunidades eclesiales intervienen en el debate público, expresando reservas o reclamando ciertos principios, esto no constituye una forma de intolerancia o una interferencia, puesto que tales intervenciones se dirigen únicamente a iluminar las conciencias, permitiéndoles actuar libre y responsablemente, según las exigencias auténticas de la justicia, incluso si esto pudiese entrar en conflicto con situaciones de poder e intereses personales". Consulta en www.vatican.va. 
de la misión de salvación, la Iglesia no puede faltar a su deber de purificar la razón mediante la propuesta de su doctrina social, argumentada "a partir de lo que es conforme a la naturaleza de todo ser humano", y de despertar las fuerzas morales y espirituales, abriendo la voluntad a las auténticas exigencias del bien (DCE 28:5).

Esta pretensión de la Iglesia es compatible con la laicidad del Estado que implica que las realidades temporales se rijan según sus propias normas; a su fundamentación y desarrollo pertenecen también las instancias éticas, ya que la política no es simple técnica ${ }^{56}$, como ha aparecido en la discusión con Habermas; estas realidades, temporales, no obstante, "encuentran su fundamento en la esencia misma del hombre y, por tanto, remiten en definitiva al creador". ${ }^{57}$

3.3. La Iglesia no debe emprender la empresa política de una sociedad más justa, pero tampoco debe quedarse al margen de la lucha por la justicia (DCE 28:6)

\subsubsection{Tesis tercera}

La Iglesia no es pues la responsable de una sociedad más justa. El texto formula con cuidados matices lo que pretende: "tratándose de un quehacer político, esto no puede ser un cometido inmediato de la Iglesia" (DCE 28:5). ${ }^{58}$ Para Benito XVI está claro que la Iglesia no tiene como cometido buscar "un orden social y estatal justo", pues éste es de orden político, aunque deja abierta la posibilidad, sin embargo, de que ése sí sea precisamente un cometido mediato de la Iglesia. Para ser más fiel al texto recurriré al mismo, de forma directa. En el entero párrafo 28, dedicado a esta cuestión, se hacen las siguientes afirmaciones que, dado el estilo dual y complementario con que está escrita la encíclica, pretenden ir aclarando una toma de posición que parece suficientemente consolidada; veámoslas sucesivamente.

En primer lugar, Benito XVI se sitúa muy claramente en la tradición cristiana -que formuló abierta y audazmente, entre otros, el jesuita Francisco

\footnotetext{
56 DCE 28.1

57 Discurso a la Conferencia Episcopal Italiana (18-V-2006). Consulta en www.vatican.va

58 Las cursivas son mías.
} 
Suárez- de distinción de planos o ámbitos (es propio de la estructura fundamental del cristianismo la distinción entre lo que es del César y lo que es de Dios, ${ }^{59}$ esto es, entre Estado e Iglesia, DCE 28:2), por lo que, como ya se ha dicho el orden justo de la sociedad y del Estado es una tarea principal de la política, siguiendo la afirmación que hace el Concilio Vaticano II sobre el reconocimiento de la autonomía de las realidades temporales. ${ }^{60}$

El Estado y la Iglesia son dos esferas distintas, pero siempre en relación recíproca (DCE 28:2), de donde se sigue que la Iglesia no puede ni debe emprender por cuenta propia la empresa política de realizar la sociedad más justa posible (DCE 28:6) por lo que no puede ni debe sustituir al Estado (DCE 28:6), lo que concluye lógicamente con la afirmación de que la sociedad justa no puede ser obra de la Iglesia, sino de la política (DCE 28:6).

El hecho de que la sociedad justa no sea tarea inmediata de la Iglesia deja a ésta en un triple papel: formación, argumentación pública y participación con iniciativas sociales.

En primer lugar, la Iglesia debe estar presente en la formación, puesto que es esencial para conseguir esta sociedad justa, pues aunque "(...) no es tarea de la Iglesia el que ella misma haga valer políticamente esta doctrina [la Doctrina Social de la Iglesia]" (DCE 28:5), la Iglesia quiere servir a la formación de las conciencias en la política (DCE 28), pues, al tratarse de una tarea humana primaria, la Iglesia tiene el deber de ofrecer, mediante la purificación de la razón y la formación ética, su contribución específica, para que las exigencias de la justicia sean comprensibles y políticamente realizables (DCE 28:5).

En segundo lugar, la argumentación pública, de tipo racional, por la que la Iglesia se inserta en la lucha por la justicia y despierta las fuerzas espirituales para permitir que la justicia sea capaz de afirmarse y prosperar, aun cuando exija renuncias, que hacen necesaria esta aportación específica cristiana. Para todo ello, a la Iglesia le interesa sobremanera trabajar por la justicia esforzándose por abrir la inteligencia y la voluntad a las exigencias del bien (DCE 28:6).

En tercer lugar, la participación desde las iniciativas sociales, pues, admitiendo que el establecimiento de estructuras justas no es un cometido inmediato de la Iglesia (DCE 29:1) y que la sociedad justa no puede ser obra (...) sino de

59 Citando el evangelio de san Mateo, Mt 22:21.

60 Citando la constitución conciliar Gaudium et Spes, GS 36. 
la política (DCE 28:6), en cualquier caso, no se trata de que el Estado regule y domine, sino que generosamente reconozca y apoye (...) las iniciativas que surgen de las diversas fuerzas sociales y que unen la espontaneidad con la cercanía a los hombres necesitados de auxilio (DCE 28:6). Según el Papa éste es lugar inmediato de la Iglesia, que es una de estas fuerzas vivas (DCE 28:6).

3.3.2. Tesis complementaria: los cristianos (seglares) tienen un deber inmediato en la tarea política, como ciudadanos del Estado y como miembros de la Iglesia (DCE 29:2).

En cuanto ciudadanos del Estado, los seglares están llamados a participar en la vida pública, a configurar rectamente la vida social, respetando su legítima autonomía, a cooperar con los otros ciudadanos, según las respectivas competencias y bajo su propia responsabilidad, en cuanto son miembros de la Iglesia los seglares están llamados a dejar que la caridad anime toda su existencia eclesial y también su actividad política vivida como "caridad social" y su actividad social, estructurada en las organizaciones caritativas de la Iglesia, que son parte de su naturaleza.

Aunque la Iglesia no deba formular soluciones concretas para los problemas (políticos, económicos, etc.) de la sociedad civil-menos aún soluciones únicas-, la Iglesia tiene el derecho y el deber de pronunciar juicios morales sobre realidades temporales, a partir del reconocimiento de "la legitimidad pluralidad de opiniones temporales" ${ }^{61}$ El cristiano que vive en la sociedad plural se mueve en ese ámbito abierto, aunque también estéllamado a disentir de una concepción del pluralismo entendido como relativismo moral, nociva para la misma vida democrática, "pues ésta tiene necesidad de fundamentos verdaderos y sólidos, esto es, de principios éticos que, por su propia naturaleza y papel fundacional de la vida social, no son "negociables»" ${ }^{62}$ Aun así ésta es una problemática que, sin casuismo, habrá que ir desarrollando para poder ejercer un verdadero discernimiento político desde la caridad política, de que habló Pío XI y retomó el concilio Vaticano II, y desde la auto-

61 Gaudium et Spes n 75.

62 Congregación para la doctrina de la fe (2002) Nota doctrinal sobre algunas cuestiones relativas al compromiso y la conducta de los católicos en la vida pública, Roma, 24-XI-2002. Era entonces prefecto de dicha Congregación Joseph Ratzinger y secretario Tarcisio Bertone, actual Secretario de Estado. 
nomía de las realidad temporales. Como propongo en la conclusión, éste es el aspecto más problemático de la propia encíclica y el que va a crear más interpretaciones contrapuestas.

\title{
4. La actividad caritativa y el voluntariado cristianos (nn 30-39)
}

El servicio caritativo eclesial en el contexto social actual se presenta, según la encíclica, de forma múltiple en un mundo empequeñecido (DCE 30:1), por el efecto que los medios de comunicación (tanto transportes, como mass media) ejercen sobre nuestra conciencia de la realidad. En cierto modo se ha acortado la distancia entre los habitantes del mundo, lo que implica, como dijo el último concilio, que la acción caritativa deba abarcar hoy a las necesidades humanas de todos los hombres. El Papa ha subrayado la "nueva disponibilidad" que estos cambios exigen en los cristianos:

\begin{abstract}
El hecho de que ahora se conozcan de manera mucho más inmediata las necesidades de los hombres es también una llamada sobre todo a compartir situaciones y dificultades. Vemos cada día lo mucho que se sufre en el mundo a causa de tantas formas de miseria material o espiritual, no obstante los grandes progresos en el campo de la ciencia y de la técnica. Así pues, el momento actual requiere una nueva disponibilidad para socorrer al prójimo necesitado (DCE 30:2).
\end{abstract}

Entre los señalados por la encíclica, como signos nuevos para la acción caritativa de la Iglesia, ${ }^{63}$ están la solidaridad civil, las nuevas formas de voluntariado y la complementariedad entre acción individual y acción organizada. No sólo nuestra conciencia de los problemas se ha hecho global sino que esta mundialización ha afectado a la capacidad de respuesta en la solidaridad, por ejemplo en la distribución de ayuda, y la ha extendido teniendo como horizonte el mundo entero. Algunos hechos resultantes de estas nuevas realidades son, por un lado, que la solidaridad expresada por la sociedad civil supera de manera notable a la realizada por las personas individualmente (DCE 30:3) y, por otro, que han surgido nuevas formas de colaboración entre entidades estatales y eclesiales, con una beneficiosa relación mutua, por ejemplo en la oportunidad para las entidades eclesiales, con la transparencia en su gestión y la fidelidad al deber de testimoniar el amor (DCE 30:4) de poder animar a las instituciones civiles y favorecer una coordinación mutua y eficaz. Otro signo, subrayado por la encíclica, es el nacimiento y difusión de diferentes formas de voluntariado, verdadera escuela de vida para los jóvenes, que educa a la

63 Llamados "signos de nuestro tiempo" en el decreto conciliar del Vaticano II Apostolicam actuositatem, n 14, citado en DCE 30:3. 
solidaridad y a estar disponibles para dar no sólo algo, sino a sí mismos (DCE 30:4). La comunidad eclesial se siente llamada a una colaboración ecuménica intracristiana y a una cooperación ecuménica interreligiosa, lo que no hace sino redundar en la necesidad de definir el perfil específico de la actividad caritativa de la Iglesia (DCE 31:1), de forma que ésta no se diluya en una organización asistencial genérica, convirtiéndose simplemente en una de tantas variantes posibles de asistencia social.

Benito XVI define este perfil de forma sencilla, al decir que la caridad cristiana es ante todo y simplemente la respuesta a una necesidad inmediata en una determinada situación (DCE 31:2), por lo que las organizaciones caritativas de la Iglesia han de hacer lo posible para poner a disposición los medios necesarios $y$, sobre todo, los hombres y mujeres que desempeñan estos cometidos (DCE 31:2) de forma que lo haga con competencia profesional, con la formación más apropiada y adecuada.

Esta acción caritativa eclesial debe responder a varios requisitos, enumerados por la encíclica bajo el epígrafe perfil específico de la creatividad caritativa de la Iglesia, siempre en pares conceptuales: "preparación profesional" y "formación del corazón"; apartidismo y "mirada samaritana"; rechazo del proselitismo y gratuidad; centralidad eclesial de la acción caritativa y espiritualidad histórica de la acción caritativa.

\section{a) Preparación profesional y "formación del corazón" (DCE 30:3)}

Para realizar plenamente ese servicio es imprescindible una buena competencia profesional, aunque la atención personal no deba ser sólo técnicamente correcta. Por eso se subraya que los servicios caritativos "necesitan humanidad". Los que trabajan en ellos deben distinguirse por no limitarse a realizar con destreza lo más conveniente en cada momento (es importante el primer subrayado, si no se quiere privilegiar unilateralmente el segundo aspecto, confundiendo una realidad que hay que entender siempre en tensión creadora), sino por su dedicación al otro con una atención que sale del corazón, para que el otro experimente su riqueza de humanidad. Para dichos agentes será necesaria no sólo la "preparación profesional", sino sobre todo una "formación del corazón" que les guíe hacia el encuentro que suscita el amor y abre al otro su espíritu,

de modo que, para ellos, el amor al prójimo ya no sea un mandamiento por así decir impuesto desde fuera, sino una consecuencia que se desprende de su fe, la cual actúa por la caridad (cf. Ga 5, 6) (DCE 30:3). 


\section{b) Independencia apartidista y "mirada samaritana" (DCE 31:3).}

La independencia apartidista de toda actividad caritativa cristiana es otra de las características esbozadas, en contraste con la carga ideológica en la transformación del mundo (especialmente la de inspiración marxista, según el Papa), que fuerza la estrategia evangélica, pues pretende ponerla al servicio de estrategias mundanas. Las ideologías del progreso, una de ellas el marxismo pero también el liberalismo, inductor de "capitalismo compasivo", al que me he referido anteriormente, pueden reducir y condicionar la identidad cristiana en el servicio, que es la actualización aquí y ahora del amor que el hombre siempre necesita. Benito XVI subraya, pues, la explícita motivación teologal que debe mover la actividad de caridad de los cristianos, aunque deje sin resolver en qué medida estos puedan participar en otras estrategias, por ejemplo la marxista o la capitalista, pero también la socialdemócrata clásica o la socio-liberal de la "tercera vía" que promueve la sociedad del bienestar. Este tema del pluralismo político de los católicos (liberalismo y socialismo, esencialmente) sí había sido abordado por los predecesores de BenitoXVI, tanto por Pablo VI en Octogesima adveniens (1971), como por Juan Pablo II en Sollicitudo rei socialis y en Centesimus agnus (1991). Esta crítica a la "filosofía del progreso", existente desde el siglo XIX, es clara; ${ }^{64}$ parece que su motivo es, sobre todo, eclesial y teologal, en orden a la defensa de la identidad de lo cristiano.

Ésta es una de las pocas ocasiones en que el estilo de la encíclica se vuelve categórico, al enfatizar que solamente se contribuye a un mundo mejor haciendo el bien ahora y en primera persona, con pasión y donde sea posible, independientemente de estrategias y programas de partido (DCE 31:3), puesto que el sacrificio del hombre que vive en el presente en aras de un futuro cuya efectiva realización resulta por lo menos dudosa sería siempre rechazable, por lo que concluye sintéticamente que no se puede promover la humanización del mundo renunciando, por el momento, a comportarse de manera humana. Parece que la preocupación central, no obstante, reside no tanto en rechazar

64 Especial atención merece en la encíclica la crítica de la visión radical marxista de la "teoría del empobrecimiento", que es presentada de la siguiente forma: quien en una situación de poder injusto ayuda al hombre con iniciativas de caridad (afirma [la mencionada teoría del empobrecimiento]) se pone de hecho al servicio de ese sistema injusto, haciéndolo aparecer soportable, al menos hasta cierto punto. Se frena así el potencial revolucionario y, por tanto, se paraliza la insurrección hacia un mundo mejor. De aquí el rechazo y el ataque a la caridad como un sistema conservador del statu quo. En realidad, ésta es una filosofía inhumana (DCE 31:3). Ésta es una de las versiones de ideología del progreso que la encíclica crítica. 
la validez, ciertamente complementaria, de otras estrategias, cuanto en su absolutización y el consiguiente rechazo del específico programa del cristiano -el programa del buen samaritano, el programa de Jesús que el Papa resume en un "corazón que ve». Sin embargo esta defensa cerrada de la identidad cristiana no excluye el valor y la deseable posible colaboración con otras estrategias por cuanto la encíclica afirma, como una obviedad, que

cuando la actividad caritativa es asumida por la Iglesia como iniciativa comunitaria, a la espontaneidad del individuo debe añadirse también la programación, la previsión, la colaboración con otras instituciones similares (DCE 31:3).

\section{c) Rechazo del proselitismo y gratuidad del compromiso (DCE 31:4).}

Puesto que la caridad no ha de ser un medio de proselitismo, la encíclica subraya, citando un reciente documento sobre el ministerio episcopal (2004) que el amor es gratuito; no se practica para obtener otros objetivos, sin que esto implique la opacidad o silencio referencial teológico o cristológico, pues, afirma la encíclica, que "la raíz más profunda del sufrimiento es precisamente la ausencia de Dios". Libertad en la invitación y actitud testimonial van unidas a la necesaria capacidad de discernimiento cristiano sobre el oportuno "tiempo de hablar de Dios" y el "tiempo de callar", sobre el servicio, acompañado de anuncio explícito y el servicio "dejando que hable sólo el amor". Lejos de ser sólo una forma de sabiduría evangelizadora, este discernimiento conlleva una verdadera existencia teologal, puesto que Dios es así. Es decir, en el Dios que es amor su nombre se muestra en la alternancia entre la Palabra y el silencio, puesto que la mejor defensa de Dios y del hombre consiste precisamente en el amor.

Por ello, las organizaciones caritativas de la Iglesia deben cuidar especialmente que en sus propios miembros esté viva esta conciencia, de modo que, sea que hablen, sea que callen y testimonien, sean siempre testigos creíbles de Cristo.

\section{d) Espiritualidad histórica de la acción caritativa.}

El servicio de la caridad es también fuente de conformación espiritual, con algunos trazos decisivos: respeto, humildad, sabiduría paciente. En primer lugar, el respeto en la manera de implicarse en la relación humana generada por el servicio; para que el don no humille al otro, no solamente debo darle algo mío, pues la participación personal en los sufrimientos del otro se convierte 
así en un darme a mí mismo, de manera que el que sirve ha de ser parte del don como persona (DCE 34). De esta forma se hace humilde el que sirve, como Cristo, que ocupó el último puesto en el mundo -la cruz-, y precisamente con esta humildad radical nos ha redimido y nos ayuda constantemente.

En segundo lugar, la humildad: para poder decir con el Evangelio "somos unos pobres siervos" $(L c 17,10)$, no hay que buscar el fundamento en la superioridad o mayor capacidad personal, sino en el don o gracia recibidos, pues, de ese modo, el que ayuda puede reconocer que también él es ayudado.

En tercer y último lugar la sabiduría paciente, ante el exceso de necesidades y los limites de las actuaciones, que pueden hacer sentir la tentación del desaliento (DCE 35). Ante la presunción de tener que mejorar el mundo-algo siempre necesario- en primera persona y por sí solo (DCE 35), el cristiano comprometido en el servicio de la caridad, adquiere y refuerza la conciencia de no ser, en definitiva, más que un instrumento en manos del Señor (DCE 35 ), que es quien gobierna el mundo es Dios. Liberarse del peso del mundo y ofrecer a esa salvación del mundo nuestro servicio sólo en lo que podemos y hasta que Él nos dé fuerzas (DCE 35), es decir, "hacer todo lo que está en nuestras manos con las capacidades que tenemos" es la justa actitud que funda un auténtico discernimiento cristiano en el compromiso por la justicia. Con frecuencia la persona comprometida en el servicio de la caridad se encuentra dividido ante "la experiencia de la inmensa necesidad" que puede derivar hacia la convicción ideológica de pretender "realizar ahora lo que, según parece, no consigue el gobierno de Dios sobre el mundo: la solución universal de todos los problemas" (DCE 36), o hacia "la inercia ante la impresión de que, en cualquier caso, no se puede hacer nada" (DCE 36).

Para intervenir en el necesario discernimiento de ambas tentaciones es sobremanera importante
el contacto vivo con Cristo [que] es la ayuda decisiva para continuar en el camino recto: ni caer en una soberbia que desprecia al hombre y en realidad nada construye, sino que más bien destruye, ni ceder a la resignación, la cual impediría dejarse guiar por el amor y así servir al hombre (DCE 36).

Esta dimensión de la vida en el espíritu es necesaria para recuperar la fundamentación del compromiso, ante el activismo yel secularismo de muchos cristianos, pues la familiaridad con Dios impide que el hombre se degrade y se convierta en juez de Dios, acusándole de permitir la miseria sin sentir compasión por sus criaturas (DCE 37).

Propone la encíclica una espiritualidad fuerte del compromiso, de manera 
que los cristianos, inmersos como los demás (DCE 38) en la misma historia, dramática y compleja, sigan creyendo, a pesar de todas las incomprensiones y confusiones del mundo que les rodea, en la «bondad de Dios y su amor al hombre» (Tt 3, 4) (DCE 38), y para ello propone creer con firmeza que Dios nos ama, aunque su silencio siga siendo incomprensible para nosotros (DCE 38) y pacientemente, no desfallecer ni siquiera ante el fracaso aparente, y reconocer y confiar en el misterio de Dios incluso en la oscuridad, de manera que la "verdad" de Dios-amor transforme nuestra impaciencia y nuestras dudas en la esperanza segura de que el mundo está en manos de Dios (DCE 39).

\section{Reflexión sobre la cuestión social y algunas valoraciones}

Hasta aquí he expuesto de forma sintética las grandes líneas de la encíclica que más interesan a la doctrina social. Para concluir propongo algunas cuestiones que probablemente suscitarán más discusión y que, en cualquier caso, parecen más destacables por su novedad o por su -aparente o real-cuestionamiento de perspectivas aceptadas hasta la fecha. Cuatro son los interrogantes para el diálogo y para la reflexión ulterior, tanto eclesial como social que, a mi juicio, suscita DCE.

\subsection{La misión de la Iglesia en la relación entre justicia y caridad}

La distinción entre la doble dimensión justicia y caridad como parte de la misión de la Iglesia parece esconder una distinción de planos: caritativo-eclesial y político-seglar. La acción o compromiso vinculante para toda la Iglesia es, según DCE, el servicio de la caridad; el servicio de la política es lo propio y específico de los seglares por medio de las estructuras políticas. Aun aceptando que esta distinción es suficientemente clara y responde a una lógica, parece que esconde el compromiso eclesial por la justicia, un compromiso que afecta al conjunto de la Iglesia. Desde el sínodo de 1971, y aún más con Pablo VI, quedaba muy claramente expresado que ese servicio de la justicia era misión de toda la Iglesia, y formaba parte de la naturaleza de la misma.

Con DCE parece que vuelve la clásica distinción, formulada por Maritain, entre la acción de los cristianos, en cuanto cristianos ("parler et agir en tant que chrétien") o como cristianos ("parler et agir en chrétien"), ${ }^{65}$ en

65 Cfr. Jacques Maritain (1999), Humanismo integral, Palabra, Madrid, pp. 353-371, traducción de Alfredo DE MEndiź́BAl sobre el original de 1936 (cfr. Jacques et Raïssa Maritain, Oeuvres 
cierta forma superada por el concilio Vaticano segundo y por la praxis y las afirmaciones del magisterio de los años 70, nunca cuestionadas por la enseñanza posterior de Juan Pablo II. En efecto, Maritain diferenciaba entre dos planos: el espiritual y el temporal, a los que añade un plano intermedio: lo espiritual en su conexión con lo temporal ${ }^{66}$ Los dos planos esenciales son distintos, pero no están separados aunque tampoco se confundan. En el primero, los cristianos actúan "como miembros del cuerpo místico de Cristo"; en el segundo "como miembros de la ciudad terrena". En ese plano, de orden intelectual o moral, científico y artístico o social y político, la actividad humana es referida a Dios como fin último, pero es determinada por objetos que no son la vida eterna, sino cosas temporales (plano mundano). Es la distinción clásica en el cristianismo, que DCE recuerda, entre las cosas de Dios y las de César. ${ }^{67}$ En el primer plano los cristianos actúan "en cuanto cristianos" (en tant que chrétien) y, en esa media, comprometen a la Iglesia; en el segundo actúan "como cristianos" (en chrétien), comprometiéndose sólo a sí mismos, aunque en la totalidad del ser personal, como ciudadanos y bautizados creyentes.

Maritain defiende una comprensión dialéctica de estas dos dimensiones, que no pueden ser separadas, como si no tuviesen nada que ver y fuesen independientes una de otra, ni ser unidas de manera que quedasen confundidas. Estas dos desviaciones, si se diesen, constituirían dentro del cristianismo una tendencia mundana o una tendencia sobrenatural.

complètes, Friburgo de Suiza - Paris, Universitaires - Saint Paul, vol. VI (1935-1938), pp. 617-634. Se trata de un texto añadido bajo el título "Estructura de la acción", publicado en el semanario de los dominicos franceses Sept, los días 12 y 26 de abril de 1935 (no es correcta la fecha de 16-IV-1935 indicada en la edición italiana, Roma 1980, Borla, ni tampoco la que figura en la citada edición española, 12-IX-1935 y 16-IV-1935).

66 "La actividad del católico se distribuye en tres planos: el plano de lo espiritual, el plano de lo temporal y el plano intermedio de lo espiritual que afecta a lo temporal", cfr. Jacques MARITAIN (1999), Oeuvres complètes, cit., p. 625. El autor subraya dos consecuencias de su exposición: estos tres ámbitos de actividad son necesarios y complementarios, ya queninguno sustituye a los otros; en el tercer plano, la unión debe ser el criterio ("le mot d'ordre"), pues sólo ella garantiza la fuerza de una determinada posición; en ese caso sólo la Santa Sede o el episcopado de un país tienen capacidad para proponer una interpretación que pretenda ser palabra de la Iglesia y no un juicio particular. Maritain, obviamente, advierte de la dificultad de tal juicio y de la necesaria educación de las masas católicas para captar esas diferencias. Por el contrario, en el segundo plano, la diversidad plural es la regla habitual, y no la unión de los católicos. En este segundo ámbito surge la acción colectiva de cristianos que, sin pretender actuar en cuanto cristianos, lo son no por denominación, sino por inspiración.

67 DCE 28:2, citando Mt 22:21. 
Maritain concibe además un verdadero tercer plano que conecta las verdades del orden temporal a las verdades reveladas, así como aquellas verdades espirituales que tienen un carácter mixto: éste es el plano de lo espiritual que converge en lo temporal, en el que el cristiano actúa en cuanto cristiano y, por ello, compromete a la Iglesia; es así, por ejemplo, en el apostolado en el que los seglares colaboran en la misión entera de la Iglesia docente. Según Maritain, en este tercer plano se ejercita "una acción cívica católica (en el sentido estricto de la expresión) cuando un seglar interviene en las cosas políticas para defender los intereses y valores religiosos y en la misma medida que la fe religiosa exige esta defensa" ${ }^{68}$ Para Maritain esta acción no es lo mismo que una obra política propiamente dicha a partir de una determinada concepción, probablemente pluralista, del bien común. Las capacidades de discernimiento y orientación no son las mismas en los dos planos.

El sínodo de 1971, dedicado a la justicia en el mundo abordó la cuestión de forma más unitaria, sin negar una eventual y posible distinción de planos, pero recogiendo lo que el propio proceso conciliar ya había afirmado, a saber la identificación entre la naturaleza y la misión de la Iglesia que consiste en la evangelización o anuncio del mensaje cristiano del que forma parte el empeño "en la liberación integral del hombre ya desde ahora, en su existencia terrena" ${ }^{69}$ Pablo VI lo reiteró en 1975, por lo que el Compendio de la doctrina social de la Iglesia dice, citando al papa Montini que la doctrina social es parte integrante del ministerio de evangelización de la Iglesia. ${ }^{70}$ La promoción humana, la acción por la justicia y el esfuerzo por la transformación de las estructuras sociales son, por lo tanto, constitutivas de la evangelización.

El Compendio de la doctrina social de la Iglesia de 2004 lo afirma reiteradamente: la Iglesia es servidora de la salvación en el contexto de la historia y del mundo en que el hombre vive; con la enseñanza social la Iglesia trata de fecundar y fermentar la sociedad misma con el evangelio; con su doctrina social la Iglesia se hace cargo del anuncio que el Señor le ha confiado para que evangelice el ámbito social, que significa promover una sociedad a me-

69 Sínodo de los Obispos (1971), La justicia en el mundo. Cfr. Los documentos del tercer Sínodo. Sacerdocio y justicia en el mundo, Madrid 1971, PPC (Nuevos folletos PPC 23-24), p. 51; se trata del texto de la Políglota vaticana.

70 Pablo VI (1975), Exhortación apostólica Evangelii nutiandi, n 29, citada en PonTiFicio Consejo "Justicia y PAZ" (2004), Compendio de la doctrina social de la Iglesia, Roma, Libreria editrice vaticana, p. 35 , n. 66 . 
dida del hombre, en cuanto una sociedad está ordenada a medida de Cristo, construir una ciudad del hombre más humana porque es más conforme al Reino de Dios; la Iglesia con su doctrina social, no sólo no se aleja de la propia misión, sino que es estrictamente fiel a ella; con su doctrina social es fiel a Cristo y se revela a los hombres como "sacramento universal de salvación"; entre evangelización y promoción humana (desarrollo, liberación) existen vínculos profundos, ${ }^{71}$ por los que la difusión de la doctrina social pertenece a su misión evangelizadora y forma parte esencial del mensaje cristiano; no estamos en presencia de un interés o de una acción marginal, que se añade a la misión de la Iglesia, sino en el corazón mismo de su ministerialidad; esta misión configura el derecho y el deber de la Iglesia a elaborar una doctrina social propia y a renovar con ella la sociedad y sus estructuras, mediante las responsabilidades y las tareas que esta doctrina suscita; por último, la doctrina social no es para la Iglesia un privilegio, una digresión, una ventaja o una injerencia: es su derecho a evangelizar el ámbito social, en el complejo mundo de la producción, del trabajo, de la empresa, de la finanza, del comercio, de la política, de la jurisprudencia, de la cultura, de las comunicaciones sociales, en el que el hombre vive. ${ }^{72}$

Me parece que esta encíclica va a reabrir un debate que, de forma sintética, podríamos resumir en las dos direcciones que "la lucha por la justicia" encuentra dentro de la Iglesia: la seglaridad específica de la misma o la eclesialidad global. Para unos la encíclica vuelve a una distinción esencial, la distinción de planos, entre lo que es misión de toda la Iglesia y en la que los cristianos actúan "en cuanto cristianos", y lo que es misión de los cristianos individualmente considerados, en la que estos actúan sólo "como cristianos", pero sin pretender representar en exclusiva la posición cristiana. En medio quedaría aquella situación en que los cristianos defienden posturas cristianas que vinculan a toda la Iglesia, pero que afectan al orden temporal, en la que están afectados muy especialmente los políticos católicos.

\subsection{Caridad como dimensión estructural y estructurante de la Iglesia}

Es posible hacer la afirmación conclusiva del párrafo anterior porque la encíclica DCE tiene a subrayar que "las organizaciones caritativas de la Igle-

71 PABLO VI (1975), Exhortación apostólica Evangelii nuntiandi, n 31.

72 Pontificio Consejo "Justicia y Paz" (2004), Compendio..., cit., pp. 32-38, nn 60-72. Los textos citados están respectivamente en los nn 60,62, 62, 63, 64, 65, 66, 67, 67, 69 y 71. 
sia" son "un opus proprium", cuyo "cometido es congenial" a la Iglesia (DCE 29:3). Parece que es evidente para el autor de DCE que esta tarea inmediata de la Iglesia es inequívocamente cristiana, una tarea de la que la Iglesia es directamente responsable, conforme a su naturaleza, y de la que nunca puede sentirse dispensada; por último, como el amor que permanece (1 Cor 13:8.13, "el amor no pasará nunca") nunca habrá situaciones en las que no haga falta la caridad de cada cristiano individualmente, porque el hombre, más allá de la justicia, tiene y tendrá siempre necesidad de amor (DCE 29:3).

La Iglesia, se ocupará en señalar con claridad el papa Ratzinger, no hace obras de caridad "a través" de las diversas organizaciones, sino que es la Iglesia "el verdadero sujeto de las diversas organizaciones católicas que desempeñan un servicio de caridad es la Iglesia misma" (DCE 32). La concepción papal del lugar central de la Iglesia en el servicio de caridad queda subrayada en la encíclica por la doble referencia a la estructura episcopal de la Iglesia y al origen apostólico de aquél (Hechos de los Apóstoles 2: 42-44). Para Benito XVI parece que las obras de caridad ocupan un lugar nuclear en la vida de la Iglesia, mientras que no afirma tan explícitamente que la acción por la justicia ocupe ese mismo lugar nuclear, aunque no lo niegue. El servicio de la caridad es una actividad de la Iglesia como tal y que forma parte esencial de su misión originaria, al igual que el servicio de la Palabra y los sacramentos (DCE 32), es decir de esa triple dimensión de que ya se ha hablado. ${ }^{73}$

La eclesialidad se abre a sintonizar con las otras organizaciones en el servicio a las diversas formas de necesidad, aunque manteniendo la identidad específica del servicio que Cristo pidió a sus discípulos (DCE 32). En el texto de DCE coexisten dos tendencias de afirmaciones que revelan una tensión. Por una parte, el servicio de la caridad es una de las tareas que expresan la naturaleza esencial de la Iglesia (DCE 25:1), pero por otra, este servicio que, sin embargo, no es una especie de actividad de asistencia social, realizado bajo el paradigma del buen samaritano (DCE 25:2 y 31:2), es una forma de acción que se sitúa dentro del compromiso por la justicia y el amor (DCE 30:1).

73 La naturaleza íntima de la Iglesia se expresa en una triple tarea: anuncio de la Palabra de Dios (kerygma-martyria), celebración de los Sacramentos (leiturgia) y servicio de la caridad (diakonia). Son tareas que se implican mutuamente y no pueden separarse una de otra. Para la Iglesia, la caridad no es una especie de actividad de asistencia social que también se podría dejar a otros, sino que pertenece a su naturaleza y es manifestación irrenunciable de su propia esencia. (DCE 25:1). 
Este servicio de la caridad se diferencia por un perfil específico (DCE 31: epígrafe del párrafo) con las siguientes características:

a) Se trata de una respuesta ante una necesidad inmediata en una situación determinada (DCE 31:1);

b) Contribuye a la promoción de la humanización del mundo, independiente de posiciones ideológicas (DCE 31:1) y de cualquier intención proselitista (DCE 31:3).

Particularmente a partir de la cautela expresada ante las ideologías del progreso del s. XIX, en especial del marxismo, se deja ver en DCE un esfuerzo por recuperar el valor y significado de la caridad, por un lado, como factor estructurante de la actividad esencial de la Iglesia, pero por otro como perfil específico de la actividad que es "propia" de la Iglesia de forma inmediata.

Con DCE es muy posible que se debata con fuerza qué dimensiones son propias de la Iglesia dentro de la lucha por la justicia. Para unos la encíclica habrá diferenciado claramente entre lo propio de toda la Iglesia ministerial en cuanto institución, el servicio de la caridad (el opus proprium) y aquello que compete específicamente a algunos de los miembros del pueblo de Dios, los seglares comprometidos políticamente, a los que irían dirigidos los centrales números 28 y 29.

\subsection{La complementariedad entre comunidad política e Iglesia como criterio} hermenéutico y "práctico" para entender y regular las mutuas relaciones

El Estado, como hemos visto, tiene como tarea el orden justo (DCE 28:2), aunque no pueda hacerlo todo, ni mucho menos pretender absorber toda esa tarea (DCE 28:7): la medida intrínseca de toda política es la justicia y, por tanto, el Estado queda definido por esta esencial dimensión. En virtud del principio de subsidiaridad, la misión de la Iglesia es, en este orden, mediata, a través de las orientaciones válidas para la sociedad que emanan de ella (DCE 27), y a través de la acción de los ciudadanos cristianos que contribuyen a la construcción del orden social: El deber inmediato de actuar a favor de un orden justo en la sociedad es más propio ${ }^{74}$ de los fieles laicos (DCE 29:2).

A partir de DCE es muy posible que se afiance la conciencia de los católicos de un profundo respeto de la autonomía de la comunidad política y de rechazo de la pretensión de un influjo directo e inmediato de la Iglesia en la política.

74 Las redondas son mías. 
Asimismo es muy probable que se debata sobre aquellas dimensiones que son propias de la Iglesia dentro de la lucha por la justicia. Para unos la encíclica habrá diferenciado claramente entre los dos ámbitos (la justicia, tarea de la política; por otro lado, la caridad, misión de la Iglesia), aun cuando, de forma complementaria, quede también definido que la Iglesia "no puede ni debe quedarse al margen de la lucha por la justicia" (DCE 28:6). Para otros, entre quienes me cuento, la encíclica vincula los tres ámbitos (orientación, caridad y compromiso) en una visión unitaria y complementaria. Podría resumirse esta afirmación con la clásica fórmula calcedoniana: distinción, pero sin confusión, es decir, complementariedad entre tres dimensiones de un solo compromiso de acción por la justicia. Por tanto, la "lucha por la justicia" (DCE 28:6) ni tiene como actor central a la comunidad eclesial ni tampoco puede ser irrelevante para ésta, de manera que pudiera inhibirse en esta lucha o quedarse al margen de la misma. Éste es el principio inestable, pero rico, de complementariedad entre comunidad política e Iglesia, que se presenta como criterio hermenéutico y "práctico" para afirmar la autonomía de lo político y el papel, esencial y específico, de la Iglesia en la construcción de un orden social.

\subsection{Una referencia problemática al derecho natural}

Una cuarta, y última, cuestión importante, suscitada por la lectura del documento, es la referencia al derecho natural. Como ya he indicado, esta referencia al derecho natural parece devolver la legitimación de la doctrina social a otro tiempo, después de haber recorrido el proceso desde una eclesiología de societas perfecta (hasta Pío XI), la metafísica social y el derecho natural (con Pío XII ${ }^{75}$ ) hsta la teología histórica y en las plurales ciencias sociales (durante el concilio Vaticano II y durante el pontificado de Pablo $\mathrm{VI}^{76}$ ) y la teología moral, como claramente expresó Juan Pablo II y recoge resumidamente el reciente Compendio, citado anteriormente. ${ }^{77}$

75 Pontificio Consejo “Justicia y Paz” (2004), Compendio..., cit., pp. 51-52, n. 93: "Una de las características de las intervenciones de Pío XII es el relieve dado a la relación entre moral y derecho [en cursiva en el original]. El Papa insiste en la noción de derecho natural [subrayado mío], como alma del ordenamiento que debe instaurarse en el plano nacional e internacional".

76 Ibid., pp. 40-41, nn 76-78; 52-56, nn 94-100.

77 Ibid., p. 38, n 72 : "la doctrina social de la Iglesia «no pertenece al ámbito de la ideología, sino al de la teología y especialmente de la teología moral»" (cursivas en el original; la cita es JuAn PABlo II (1987) Encíclica Sollicitudo rei socialis, n 41). 
Parece lógico que a muchos lectores resulte sorprendente la redacción del párrafo en que se afirma:

La doctrina social de la Iglesia argumenta desde la razón y el derecho natural, es decir, a partir de lo que es conforme a la naturaleza de todo ser humano. Y sabe que no es tarea de la Iglesia el que ella misma haga valer políticamente esta doctrina: quiere servir a la formación de las conciencias en la política y contribuir a que crezca la percepción de las verdaderas exigencias de la justicia y, al mismo tiempo, la disponibilidad para actuar conforme a ella, aun cuando esto estuviera en contraste con situaciones de intereses personales (DCE 28:5).

Como ha escrito Luis González-Carvajal, "si el magisterio social de la Iglesia argumentara solamente a partir de la razón, no se entiende por qué estaría más libre de errores que la 'razón práctica'. De hecho, Joseph Ratzinger escribió, cuando todavía era profesor de la Facultad de Teología de Munich, que, a través del derecho natural, entraron por la puerta trasera, primero en la teología y más tarde en las declaraciones pontificias, ideas ajenas al cristianismo". ${ }^{78}$ Lo que sugiere este aparente "retroceso" en el estatuto epistemológico de la doctrina social es que nos encontramos nuevamente con una de aquellas "oscilaciones acerca de la naturaleza, el método y la estructura epistemológica" de aquella. ${ }^{79}$

Cuando el Compendio de la doctrina social de la Iglesia, publicado en el último año del pontificado de Juan Pablo II (la carta del secretario de Estado está fechada el 29-VI-2004), parecía apuntar a una evolución de este estatuto epistemológico de la doctrina social como teología moral, que es la categoría con la que Juan Pablo II se refirió a ella ${ }^{80}$, nos encontramos ahora con una nueva "oscilación" que no parece claro a dónde apunta. Es posible que ésta sea una vía pretendida para un diálogo cultural como el que el cardenal Ratzinger, el año anterior a su elección papal, había mantenido con intelectuales diferentes como Jürgen Habermas o Marcello Pera. ${ }^{81}$ Ésta primera opción proporcionaría un lenguaje filosófico comprensible por otras tradiciones y la habilitaría para una discusión en medio de la plaza pública. Pretender que la doctrina social es filosofía práctica no sólo es legítimo, sino muy útil para el diálogo en la construcción europea, que a Benito XVI parece una misión

78 Cfr. Luis González-Carvajal SantabáRbara (2006), art. cit., p. 30.

79 Pontificio Consejo “Justicia y Paz” (2004), Compendio..., cit., p. 38, n 72.

80 Sollicitudo rei socialis, 1987.

81 Cfr. la pequeña noticia aparecida sobre el libro de M. Pera y J. Ratzinger, en RFS 61 (2006), p. 279 . 
eclesial de primer orden. Pero cabe otra interpretación, quizá menos clara y desde luego menos ocasional, pero muy acorde con el talante del Papa. El intento de fundar la doctrina social para que ésta argumente desde la razón y el derecho natural, es decir, a partir de lo que es conforme a la naturaleza de todo ser humano dotaría a la doctrina social de una lógica y una arquitectura sólidas, menos útiles para la acción inmediata política ("no es tarea de la Iglesia el que ella misma haga valer políticamente esta doctrina"), pero más consistentes y coherentes para la formación de las conciencias en la políti$c a$, para la contribución en la percepción de las verdaderas exigencias de la justicia y, al mismo tiempo, la disponibilidad para actuar conforme a ella. Las tres razones apuntan, por tanto, a lo que Benito XVI considera esencial, en su concepción eclesiológica de evangelización: formación, búsqueda de la verdad y apertura a otros comportamientos.

Por último, hay que constatar el cambio que suponen ciertos planteamientos en relación con el documento orientativo de la congregación para la Doctrina de la Fe sobre el compromiso público de los católicos. ${ }^{82}$ En éste se partía de un juicio sumamente negativo sobre el pluralismo ético y su influjo en la calidad democrática, se hacía una remisión a la ética natural en relación con el relativismo ético y se llegaba a afirmar que "esta concepción relativista del pluralismo no tiene nada que ver con la legítima libertad de los ciudadanos católicos" para que estos puedan elegir libremente, entre las opiniones políticas, "aquella que, según el propio criterio, se conforma mejor a las exigencias del bien común". ${ }^{83} \mathrm{Si}$ bien en aquel documento se defiende la pluralidad de orientaciones y soluciones y que no es tarea de la Iglesia formular soluciones concretas, y menos únicas, para las cuestiones temporales, se subraya también con energía que "la Iglesia tiene el derecho y el deber de pronunciar juicios morales sobre realidades temporales cuando lo exija la fe o la ley moral", ${ }^{84}$ proclamando inmediatamente a continuación la invitación al cristiano "de disentir de una concepción del pluralismo en clave de relativismo moral". 85

82 Congregación Para la Doctrina de la Fe (2003), Nota doctrinal sobre algunas cuestiones relativas al compromiso y la conducta de los católicos en la vida pública (24 noviembre 2003). El responsable del dicasterio en ese momento era el cardenal Joseph Ratzinger.

83 Congregación para la Doctrina de la Fe (2003), Nota..., cit., nn 2:2 y 3:1.

84 Este texto cita la Constitución pastoral del concilio Vaticano II Gaudium et spes, n 14, de 7-XII-1965.

85 Ibid., n 3:1. 


\section{Conclusión}

DCE, como encíclica postsocial, en cierto sentido parece un documento menos político que el magisterio social de Pablo VI y el de Juan Pablo II. Aun así, podría sorprender la extensión que Benito XVI concede a la reflexión referida a la justicia social y a la política (nn 26-29), que es, a nuestro juicio, una de las partes más importantes del documento desde el punto de vista filosófico social, como he intentado mostrar. ${ }^{86}$

El documento usa frecuentemente un estilo de afirmaciones binarias, raramente dialécticas o categóricas. Normalmente una afirmación esencial es complementada y, por tanto, aclarada por otra afirmación, no menos esencial, pero que destruye la univocidad y simplicidad del discurso, al mismo tiempo que se procuran evitar ambigüedades, lo que no siempre se ha conseguido. Ésa es la fuerza y la debilidad del lenguaje analógico. Probablemente habremos de acostumbrarnos a este estilo de argumentación analógica del Papa para interpretar sus documentos. Concluyo, pues, mi escrito, intentando hacer una lectura más personal de dos cuestiones, especialmente relevantes, que DCE deja abiertas, como horizontes o como problemas, a partir del propio género que la encíclica utiliza desde el comienzo, el género de las afirmaciones binarias.

A. Éros y ágapê marcan una forma de relación a justicia y amor. En esta tensión entre justicia y amor la encíclica DCE muestra también una admirable unidad interna lógica. Ambas dimensiones (éros yágapê), cada una constitutiva del amor humano en plenitud, reclaman no ser vividas separadamente una de la otra, aunque sean cada una de ellas deba ser considerada en su propia entidad; ambas dimensiones pueden deteriorarse en cada persona y en su progreso social, pero ambas pueden desarrollar en plenitud la naturaleza humana y social y convertirse, por así decirlo, en mandato, porque antes han sido un don entregado a los hombres. Sólo desde el amor fundante del ser cristiano como respuesta al "acontecimiento" del amor, es comprensible, cristianamente, la lucha por la justicia y la opción por los pobres. La relación analógica hace entender que, sin reducir ni vaciar la dimensión esencial de la justicia como virtud cristiana, ésta queda sólo integralmente comprendida como momento segundo de un amor originario. El carácter cristiano de la justicia no puede sustraerse a un humanismo integral, plenamente humano y plenamente abierto a su dimensión trascendente.

86 En la conferencia de prensa citada al comienzo del artículo, el cardenal Renato R. Martino centró su exposición en estos números (26-29). 
Este horizonte deja abiertos algunos desarrollos, de los que destacaremos sólo dos. Por un lado, el carácter no primero ni fundante de la justicia en el ser del creyente y en el compromiso cristiano, si no es entendida aquélla desde el amor, libera a la Iglesia de la sobrecarga de la transformación social, sin liberarla sin embargo de estar activamente presente en la lucha por esa transformación. Ésta nos parece una de las aperturas más notables aportadas por la encíclica, pues siendo central en el cristianismo el compromiso por la justicia no es lo central. Para decirlo con palabras de Pablo VI, podemos recordar que, cuando éste subrayaba el carácter inspirador del cristianismo en "la acción a favor de la justicia social (...) para dar respuesta a las necesidades nuevas de un mundo en transformación", lo hacía para decir inmediatamente que "la Iglesia (...) camina unida a la humanidad y se solidariza con su suerte en el seno de la historia", iluminando y ayudando a esa humanidad "a corresponder al designio de amor de Dios y a realizar la plenitud de sus aspiraciones", puesto que "el Espíritu del Señor continúa su obra en el corazón de los hombres y congrega por todas partes comunidades cristianas conscientes de su responsabilidad en la sociedad". ${ }^{87}$ Es la respuesta solidaria de los hombres al amor de Dios y la confianza en la acción histórico-social del Espíritu la que define a la acción a favor de la justicia social. Conviene que el cristianismo, y más en concreto, la Iglesia católica, recupere el sentido trascendente de la acción por la justicia.

En segundo lugar, sin embargo, DCE podría sugerir una interpretación, a nuestro juicio infundada, en que la acción por la justicia quedase devaluada como algo secundario o marginal en la Iglesia, y en todo caso no perteneciente a su misterio. Es cierto que el énfasis puesto por el Papa en la acción caritativa como tarea inmediata de la Iglesia puede hacer que algunos lo interpreten así, pero por las razones expuestas anteriormente nos parece una lectura reductora. La relación entre amor y justicia no es de exclusión ni de contraposición, sino de "purificación" sin confusión ni anulación, como sugiere el mismo término empleado por el Papa. La justicia, desenraizada del amor que la fundamenta podría convertirse en un ídolo de la ciudad, la acción por la justicia podría devenir en acción idolátrica, como el éros desnaturalizado y absolutizado puede convertirse en una concepción idolátrica y reductora del hombre a algo que no es plenamente humano. Cabe otra concepción, cabe una mirada icónica de la justicia que es concebida trascendentalmente como respuesta dialógica al don del amor; podríamos

87 Pablo VI (1971), Octogesima adveniens, nn 1-2. 
hablar de una concepción plenamente válida de la justicia en la medida que ésta se presenta como icono de la justicia inmortal de Dios, lo que, siguiendo la terminología de K. Rahner, ${ }^{88}$ entenderíamos como la afirmación categorial de una justicia que es anticipación de la justicia absoluta. Una concepción icónica no permite la absolutización de ninguna acción justicia humana y la libera, por lo mismo, de su posible corrupción y deslizamiento en injusticia. Me parece ésta la interpretación más plausible de la encíclica, aunque creo que abre a otra interpretación reductora de la justicia a la caridad como tarea propia de la Iglesia y a una cierto desentendimiento de la Iglesia en la acción por la justicia. Por todo ello, para concluir esta primera consideración, subrayo lo acertado de la afirmación de padre Sorge: "La caridad estimula el progreso de la justicia". ${ }^{89}$

B. La caridad, ¿una dimensión estructurante de la Iglesia, pero excluyente del compromiso social de ésta? La encíclica resulta suficientemente clara y explícita en este aspecto, pero por eso precisamente puede ocultar otra afirmación: forma parte de la naturaleza y de la misión de la Iglesia, de la evangelización, la acción por la justicia. Como declaró el documento final del Sínodo de 1971:

\begin{abstract}
La situación actual del mundo, vista a la luz de la fe, nos invita a volver al núcleo mismo del mensaje cristiano, creando en nosotros la íntima conciencia de su verdadero sentido y de sus urgentes exigencias. La misión de predicar el Evangelio en el tiempo presente requiere que nos empeñemos en la liberación integral del hombre ya desde ahora, en su existencia terrena. En efecto, si el mensaje cristiano sobre el amor y la justicia no manifiesta su eficacia en la acción por la justicia en el mundo, muy difícilmente obtendrá credibilidad entre los hombres de nuestro tiempo. ${ }^{90}$
\end{abstract}

¿Qué es prioritaria: la acción transformadora por la justicia o por el servicio eclesial de la caridad? Éste nos parece un mal dilema, si es formulado de forma excluyente. Preferiría hacerlo de forma integradora, como hace Sorge en el artículo citado: "El camino recorrido por los seglares cristianos,

88 Cfr. K. RAHNER (1970), Diccionario teológico, Barcelona, Herder (Friburgo de Brisgovia, 1961) $745-746$.

89 Cfr. B. Sorge (2006), 282; esta afirmación podría completarse con lo que afirma el Compendio..., cit., n 206: "La caridad presupone y trasciende la justicia (...) No se pueden regular las relaciones humanas únicamente con la medida de la justicia". El mismo documento, citando a Juan Pablo II ((1980), Dives in misericordia, n 14, dice que la justicia "en todas las esferas de las relaciones interhumanas, debe experimentar, por decirlo así, una notable "corrección por parte del amor"”.

90 Sínodo de los Obispos (1971), La justicia en el mundo, cit, p. 51. 
desde la mitad del siglo XIX hasta hoy, les ha llevado a la conciencia de que las obras de caridad no deben sustituir el compromiso por la justicia social". Al subrayar la encíclica, de tal manera, el carácter de la acción caritativa como tarea propia de la Iglesia, podría llevar a la conclusión de que la acción por la justicia no lo fuere. DCE establece claramente, como he mostrado, la diferencia entre la tarea inmediata (acción caritativa) y las dos mediatas (orientación ética y acción política institucional de los seglares cristianos) de la Iglesia. Esta diferencia, sin embargo, no puede oscurecer que aún no siendo inmediata la acción de la Iglesia en ambos ámbitos, sí es tarea suya propia y por tanto esencial para comprender su naturaleza y misión; es decir, que la lógica del servicio (DCE 35) no puede oscurecer la lógica de la lucha por la justicia (DCE 28:6), a lo que pudiera dar lugar una interpretación no integral de la encíclica. DCE va a ser, sin duda, la encíclica de los movimientos eclesiales de acción caritativa y social, pero no puede serlo en detrimento de la misión de las comunidades cristianas comprometidas en la acción por la justicia y conscientes de su responsabilidad en la sociedad, como tales comunidades. Una lectura apresurada o interesada de la encíclica podría sugerir un repliegue eclesiocéntrico, en detrimento del compromiso por una evangelización integral que conlleva la liberación humana.

La gran ausencia de esta encíclica es el desconocimiento casi total de la importancia de la dimensión estructural, también como opus proprium, aunque sea mediato, es decir no de la Iglesia, constituida jerárquicamente, en cuanto pueblo de Dios, sino de los cristianos bautizados y de las comunidades cristianas en cuanto miembros de la sociedad. La gran divergencia se puede producir si la acción caritativa se convierte en el centro de esta dimensión de justicia, propia de la Iglesia jerárquica, y la acción política se deja como tarea de los seglares individualmente (el documento no habla, en esos contextos, de comunidades cristianas, colectivamente consideradas, como era frecuente en Pablo VI y aunque menos también en Juan Pablo II).

Paradójicamente, una Iglesia centrada en el servicio de la caridad, dejaría el servicio de la política fuera de su centralidad como pueblo de Dios jerárquico y lo encomendaría a los seglares en cuanto cristianos en las estructuras temporales (en cuanto ciudadanos). Este paso es problemático, pues refuerza una división entre la centralidad eclesial y la seglaridad temporal, superado inicialmente por la concepción eclesial conciliar más unitaria. Esta dualidad nos lleva a una pregunta a propósito del pluralismo de los ciudadanos católicos: ¿está éste limitado por las orientaciones éticas de la Iglesia jerárquica?, ¿de qué forma? Afirmado el pluralismo por el magisterio, en el 
concilio y especialmente después por Pablo VI (Octogesima adveniens), este pluralismo político de los católicos es ya un hecho (y un derecho) adquirido de tal manera en la conciencia social que resulta difícil pensar en una vuelta atrás. Aun así este documento, como he intentado mostrar anteriormente, podría implicar una cierta revisión de ese pluralismo, al considerar que la acción de los católicos es la tarea mediata de la Iglesia a través de los seglares en lo que sería su dimensión propia (subrayada ya por el Concilio y mantenida por todo el magisterio de Juan Pablo II). Sin por un lado, como acabo de subrayar el documento mantiene una dualidad entre eclesialidad y seglaridad de la acción política, pareciendo excluir a la Iglesia en su conjunto de la acción por la justicia, por otro lado tampoco parece claramente afirmar la complejidad y la secularizad de la sociedad civil y del cuerpo político.

La "recepción" eclesial y teológica, además de la social, que será menos relevante, que vaya haciéndose de los nuevos planteamientos de DCE, va a tener una importancia grande en la orientación y desarrollo de los planteamientos más urgentes o problemáticos que presenta la encíclica. Por la naturaleza programática del documento y por el estilo intelectual de escritura su autor, no tan pastoral, parenético o político como los anteriores Papas, nos encontramos ante un texto abierto, de complejidad elevada tras su aparente sencillez y real elegancia y belleza. Deus caritas est podría marcar un cierto "retour en arrière", según una lectura, pero también puede señalar una renovación crítica de ciertas categorías del pensamiento social cristiano, que he intentado mostrar. Razonablemente podemos esperar y apostar por la renovación y la lectura crítica. En cualquier caso, como dijo san Pablo, la última en la subsistencia temporal, la más grande de las capacidades del creyente "es el amor" (1 Cor 13: 13). 